\title{
The morphology of craters on Mercury: Results from MESSENGER flybys
}

\author{
Olivier S. Barnouin ${ }^{\mathrm{a}, *}$, Maria T. Zuber ${ }^{\mathrm{b}}$, David E. Smith ${ }^{\mathrm{b}}$, Gregory A. Neumann ${ }^{\mathrm{c}}$, Robert R. Herrick ${ }^{\mathrm{d}}$, \\ John E. Chappelow ${ }^{\mathrm{e}}$, Scott L. Murchie ${ }^{\mathrm{a}}$, Louise M. Prockter ${ }^{\mathrm{a}}$ \\ ${ }^{a}$ The Johns Hopkins University, Applied Physics Laboratory, Johns Hopkins Road, Laurel, MD 20723, USA \\ ${ }^{\mathrm{b}}$ Dept. of Earth, Atmospheric, and Planetary Sciences, Massachusetts Institute of Technology, 77 Massachusetts Ave., Cambridge, MA 02139-4307, USA \\ ${ }^{\mathrm{C}}$ NASA Goddard Space Flight Center, 8800 Greenbelt Road, Greenbelt, MD 20771, USA \\ d Geophysical Institute, University of Alaska Fairbanks, 903 Koyukuk Dr., Fairbanks, AK 99775-7320, USA \\ e SAGA Inc., 1148 Sundance Loop, Fairbanks, AK 99709, USA
}

\section{A R T I C L E I N F O}

\section{Article history:}

Received 29 November 2011

Revised 21 February 2012

Accepted 23 February 2012

Available online 6 March 2012

\section{Keywords:}

Mercury

Impact processes

Image proecessing

\begin{abstract}
A B S T R A C T
Topographic data measured from the Mercury Laser Altimeter (MLA) and the Mercury Dual Imaging System (MDIS) aboard the MESSENGER spacecraft were used for investigations of the relationship between depth and diameter for impact craters on Mercury. Results using data from the MESSENGER flybys of the innermost planet indicate that most of the craters measured with MLA are shallower than those previously measured by using Mariner 10 images. MDIS images of these same MLA-measured craters show that they have been modified. The use of shadow measurement techniques, which were found to be accurate relative to the MLA results, indicate that both small bowl-shaped and large complex craters that are fresh possess depth-to-diameter ratios that are in good agreement with those measured from Mariner 10 images. The preliminary data also show that the depths of modified craters are shallower relative to fresh ones, and might provide quantitative estimates of crater in-filling by subsequent volcanic or impact processes. The diameter that defines the transition from simple to complex craters on Mercury based on MESSENGER data is consistent with that reported from Mariner 10 data.
\end{abstract}

(c) 2012 Elsevier Inc. All rights reserved.

\section{Introduction}

The study of crater morphology on asteroids and planets has shown that several factors influence the shape of craters when they are first formed. These factors include the density, strength, porosity, nature of the porosity (macro- versus micro-porosity), heterogeneities, and curvature of the target surface (e.g., Cintala et al., 1978; Fujiwara et al., 1993; Holsapple, 1993; Asphaug et al., 1996; Cheng and Barnouin-Jha, 1999; Housen and Holsapple, 2003; Schultz et al., 2005; Barnouin-Jha et al., 2003, 2005); the mass, velocity, and impact angle of the projectile (e.g., Gault et al., 1968; Gault and Wedekind, 1978; Holsapple, 1993); and the planetary surface gravity (e.g., Gault and Wedekind, 1977; Holsapple, 1993). The dimensions of craters traditionally used to investigate these influencing factors (Pike, 1974, 1976, 1977) include the crater diameter, $D$, defined as the distance through the crater center between rim crests, and the crater depth, $d$, defined as the difference in elevation between the average height of the rim crests and the deepest point in the crater (Fig. 1; see Table 1 for variable definitions).

\footnotetext{
* Corresponding author.

E-mail address: olivier.barnouin@jhuapl.edu (O.S. Barnouin).
}

By carefully measuring these parameters for the freshest craters possible on several planetary surfaces including Mercury, Pike $(1980,1988)$ demonstrated that the gravitational acceleration at the target planet surface plays a major role in the transition of the morphology from simple bowl-shaped craters to complex craters, which possess terraces, central peaks, and flat floors (Fig. 2). These studies also reveal that the crater diameter, $D_{t}$, at which the transition from simple to complex crater morphology occurs, is between a factor of 1.5 (Garvin and Frawley, 1998) and two times greater than on Mercury despite the similarity in gravity between Mercury $\left(3.70 \mathrm{~m} / \mathrm{s}^{2}\right)$ and Mars $\left(3.72 \mathrm{~m} / \mathrm{s}^{2}\right)$. Pike $(1980,1988)$ suggested that the cause may be differences in the apparent strength (cohesion) of the surface of Mercury relative to Mars, which is richer in volatiles and possesses sedimentary rocks that are likely weaker. The small values of $D_{t}$ observed on the icy Galilean satellites (Fig. 2) relative to the Moon add credence to this view, as the crusts on these satellites are volatile rich and may thus be comparatively weak (Schenk, 2002) while possessing gravity fields comparable to that of the Moon.

Schultz (1988) proposed that differences in both impact velocity and projectile-to-target density ratios may be additional contributors to the variations in $D_{t}$ for planetary bodies with comparable gravity. The most common impact velocity is expected to be $42 \mathrm{~km} / \mathrm{s}$ on Mercury and $13 \mathrm{~km} / \mathrm{s}$ on Mars (Hartmann, 1981; 


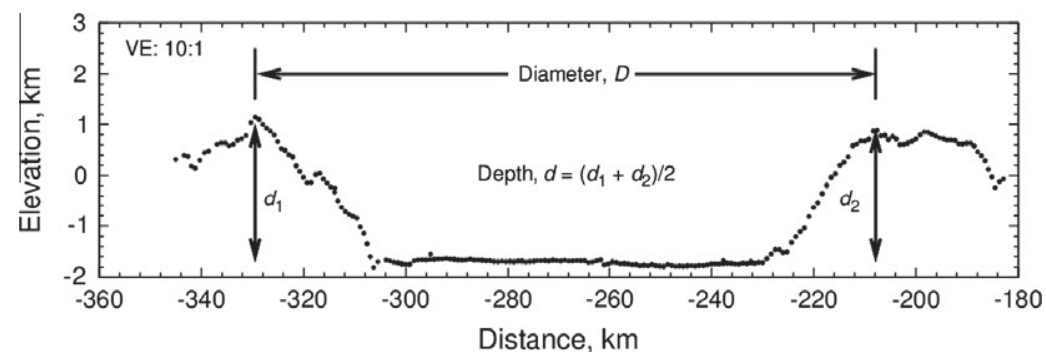

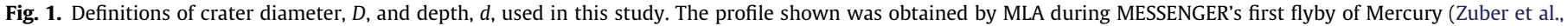
2008). The vertical exaggeration (VE) is 10 to 1.

Table 1

Definition of variables.

\begin{tabular}{ll}
\hline Variable & Definition \\
\hline$D$ & Crater rim-to-rim diameter \\
$d$ & Crater depth from rim crest to crater bottom \\
$d / D$ & Crater depth to diameter ratio \\
$D_{t}$ & Crater transition diameter from simple to complex craters \\
$e$ & Emission angle from surface normal to camera \\
$i$ & Solar incidence angle from surface normal to Sun \\
\hline
\end{tabular}

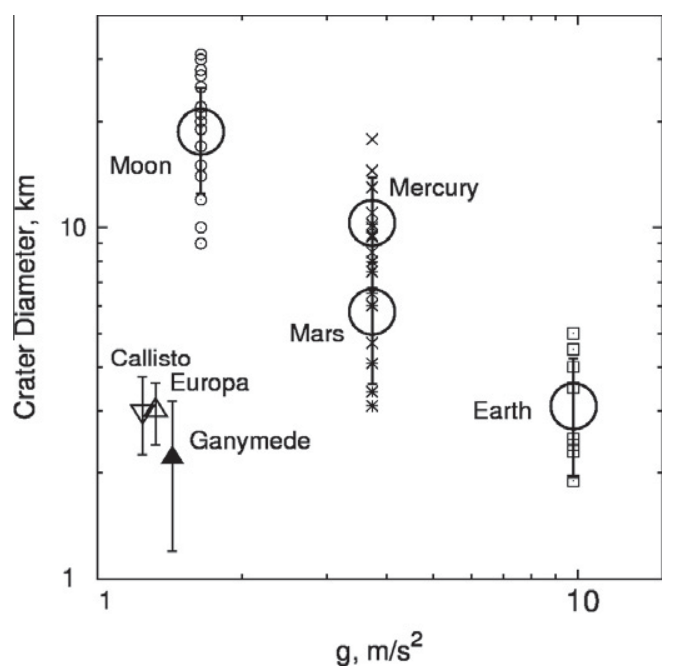

Fig. 2. Diameter at which craters transition from simple bowl-shaped to complex craters as a function of surface gravitational acceleration for the Moon (Pike, 1980), Mercury (Pike, 1988), Mars (Pike, 1980), Earth (Pike, 1980), Europa, Ganymede, and Callisto (Schenk, 2002). Large symbols are the geometric means of all the variables considered when assessing this transition. Small symbols represent the various types of data used to derive the geometric mean and include the intersection of the $d$-to- $D$ curves for simple and complex craters, when flat floors and terraces are first observed, and so on (see Pike, 1980, 1988, for additional details).

Horedt and Neukum, 1984; Schultz, 1988; Neukum and Ivanov, 1994; Le Feuvre and Wieczorek, 2008). On the basis of a large body of experimental evidence for impacts into both solid and granular targets, Schultz (1988) indicated that higher impact velocities tend to generate shallower transient crater cavities relative to their diameter, which result in less collapse during crater modification than an equivalent sized crater formed at lower impact speeds. Although recently disputed (Strom et al., 2005), some authors had proposed that projectiles impacting Mercury are likely to be cometary, and thus lower in density than those impactors at Mars, where asteroidal projectiles are probably more common (Hartmann, 1981; Horedt and Neukum, 1984; Schultz, 1988; Neukum and Ivanov, 1994). Low-density projectiles reduce the transient depth to diameter ratio of craters because these projectiles do not penetrate into the target as effectively as do higher density projectiles. Due to this combination of the higher impact velocity and lower projectile density, Mercury transient craters are expected to be shallow before gravitational forces lead to their isostatic adjustment. As a result, larger values of the crater diameter $D$ are permitted on Mercury before complex crater morphologies are formed relative to other planets where projectiles might be denser and travel more slowly.

Understanding the factors controlling the dimensions of craters during their formation not only yields information on how impact conditions on Mercury might differ from those on the Moon and Mars, but also provides a quantitative basis with which to assess the extent of crater degradation by other impact or endogenic processes (Guest and Gault, 1976; Head et al., 1976; Malin and Dzurisin, 1977, 1978; Oberbeck et al., 1977). Changes in $d, D$, and even in the resulting $D_{t}$ are all possible. Re-examining such a framework is particularly important in the case of Mercury, where new results indicate the presence of widespread volcanism in large impact basins and intercrater plains (Head et al., 2008, 2009; Murchie et al., 2008; Strom et al., 2008; Denevi et al., 2009). Modification by subsequent impacts (e.g., ejecta in-filling, impact erosion, and seismic shaking) continue to influence the shape of craters as well, but possibly to a lesser extent than previously thought (Cintala et al., 1977; Dzurisin, 1978; Wilhelms, 1976; Oberbeck et al., 1977; Spudis and Guest, 1988). Careful analysis of topographic observations and images of craters at various states of preservation provides a quantitative route to assess how volcanic and subsequent impact processes have altered the surface of Mercury (e.g., McCauley et al., 1981; Malin and Dzurisin, 1977, 1978), possibly leading to insights on the thermal evolution of this planet.

In order to assess quantitatively both the factors influencing the topography of initial formed craters on Mercury and those affected subsequently by modification processes, the state of crater degradation needs to be tracked. The levels of crater degradation on Mercury are well defined in a variety of studies based on Mariner 10 data (Cintala et al., 1976; Head et al., 1976; Malin and Dzurisin, 1977, 1978; Oberbeck et al., 1977; Spudis and Guest, 1988). These well-established criteria can be used for determining the state of degradation of each crater investigated (Pohn and Offield, 1970; McCauley et al., 1981; Spudis and Prosser, 1984; Spudis and Guest, 1988).

We use the data collected by the Mercury Laser Altimeter (MLA) and Mercury Dual Imaging System (MDIS) on board the Mercury Surface, Space ENvironment, GEochemistry, and Ranging (MESSENGER) spacecraft during its flybys of the inner planet to assess the morphology of both fresh and degraded craters on Mercury. Through the use of both instruments, we circumvent some of the pitfalls associated with traditional photoclinometry and shadow-length techniques for measuring crater depth and rim height (Pike, 1988). Use of these traditional techniques with Mariner 10 data has led various authors to report significant variations in the relationship between $d$ and $D$ (see Pike, 1988, 
for details). Pike (1988), for instance, reported a $4 \mathrm{~km}$ change in estimated $D_{t}$ for Mercury from $10 \mathrm{~km}$ to $14 \mathrm{~km}$ between his 1980 and 1988 studies. It is expected that MLA and MDIS observations obtained from the flybys and the orbital mission will provide complementary data to further assess and improve estimates of $D_{t}$ determined by Pike (1988). In fact, no significant difference may be found given our past martian experience. In this latter case, the measurement of $d$ and $D$ obtained from individual Mars Orbiter Laser Altimeter (MOLA) tracks were found to be statistically identical to those measured 20 years earlier by Pike (1980) using the traditional techniques with data from the Viking mission (Garvin and Frawley, 1998; Boyce and Garbeil, 2007). Only a small increase was found in the value of $D_{t}$ on Mars, which increased from 6-7 km to $7-8 \mathrm{~km}$, mainly because of the larger number of craters investigated in more recent studies. But the Viking data were of better resolution than the Mariner 10 data, and the trajectory, illumination and spacecraft attitude were better known.

The data obtained by the MESSENGER spacecraft are of superior quality relative to Mariner 10 . During the flybys, MLA provided a direct measurement of the surface topography for two transects that exceeded $3000 \mathrm{~km}$ along the planet's equator (Zuber et al., 2008), which Mariner 10 could not provide since it had no laser altimeter. While not used in this study, MLA orbital data provides up to two $6000 \mathrm{~km}$ tracks daily, depending on thermal and power constraints (Zuber et al., 2012). During the flybys, the MDIS instrument collected high-resolution images ( $>50 \mathrm{~m} /$ pixel) of several regions investigated by MLA during the flybys. MDIS is also collecting additional data that can be used with MLA during MESSENGER's orbital phase, but these data will be employed in a follow-on study. The MDIS images obtained during the flyby are very useful for assessing the location of the MLA data relative to the center of craters. The images also provide an accurate measure of crater diameter and an assessment of their degradation state. The topography from both instruments obtained during the flybys allows an assessment of the original $d / D$ values measured from Mariner 10 , and provides some new views on the factors that are responsible for the formation and subsequent evolution of craters on Mercury. In addition, this early look provides a preview of the analysis that can be carried out with better quality data to understand crater formation and evolution on Mercury once all of the MESSENGER orbital data are acquired and analyzed.

\section{Measurements of crater diameter and depth from MLA and MDIS}

Three types of topographic data are available from MESSENGER. The first data type is obtained by combining MDIS images with MLA transects collected during the flybys of Mercury and the subsequent orbital mission. In this study we will focus on the data collected during the two flybys, where data were collected along the equator of Mercury at approximately $15-90^{\circ} \mathrm{E}$, and $210-290^{\circ} \mathrm{E}$ (Figs. 3 and 4). The second data type is derived from the length of shadows within craters measured from a series of MDIS narrow (NAC) and wide angle camera (WAC) images acquired in regions from $45^{\circ}$ and $110^{\circ} \mathrm{E}$ and $250^{\circ}$ and $300^{\circ} \mathrm{E}$ with fairly low Sun angles. A third data type is derived from NAC and WAC images where either geometric stereo (Wewel et al., 2000; Gwinner et al., 2000; Scholten and Gwinner, 2004; Scholten et al., 2005) or photoclinometric stereo (Gaskell et al., 2008) techniques provide digital elevation models (DEMs) at several locations around the planet (Oberst et al., 2010).

This study focuses on the use of the shadow length technique in addition to the MLA-MDIS combination. This approach is necessary to increase the total number of craters measured, especially at sizes $<10 \mathrm{~km}$ in diameter. Craters of this scale that are well-resolved by the MLA-MDIS data are few, primarily because of the large $\sim 800 \mathrm{~m}$ spacing between 20 and $30 \mathrm{~m}$ diameter footprints typically obtained by MLA. Furthermore, MLA data do not frequently include craters that are particularly fresh, and thus indicative of the cratering processes affecting their formation. The DEMs derived with stereo techniques available at the time of this study were also not of sufficiently high resolution to be employed in this study. The shadow length technique provided the complementary measurements of $d$ and $D$ needed to obtain sufficient statistics. This section describes how these two topographic datasets (altimetry and shadow measurements) were used to measure $d$ and $D$ and describes the tests employed to assess the quality of the results obtained using the two approaches.

\subsection{Combined MLA-MDIS measurements}

Zuber et al. (2008) provide a discussion of the acquisition and analysis of the topographic profile obtained by the MLA during the first flyby of Mercury. Also included therein is an assessment of the roughness properties of the impact craters encountered along the profile.

For the purpose of measuring the shapes of craters, usable returns from the MLA were obtained up to a range of $1500 \mathrm{~km}$ from the surface. Spurious noise counts were removed using as a guide the two channels of MLA that retrieve returns from the surface of Mercury with the greatest likelihood (Cavanaugh et al., 2007). As a further caution, we flagged returns as noise when the point-topoint slope along the profile significantly exceeded the angle of repose $\left(>32^{\circ}\right)$. With these refinements, the resulting MLA data were of very good quality, with a typical footprint size varying from 23 to $134 \mathrm{~m}$ and with a shot spacing that varied from 725 to $888 \mathrm{~m}$ (Zuber et al., 2008). The large variation in footprint is due to the wide range of distance to the surface over which MLA operates. Some small uncertainties exist in the along-track solutions for the spacecraft, which translate to less than one shot spacing on the surface of Mercury.

The profiles obtained by MLA were correlated with surface features seen by the MDIS instrument. For the correlations shown in Figs. 3 and 4, for example, we used high-resolution mosaics (50$500 \mathrm{~m}$ per pixel) obtained with the WAC and NAC camera using the most up to date spacecraft navigation and pointing data, and the best camera distortion model available (June 2011). Following this processing, good alignments were found between the MLA footprints and features observed in the NAC images. At most, a few pixel offset exists between any surface structure and the MLA measurements. These largest errors usually occur when using the highly smeared reprojections of image data taken near the limb of Mercury that occurred with images obtained during the flyby. We typically could not make reliable crater identifications in these areas.

Fig. 5 illustrates how $d$ and $D$ of craters were measured using a combination of MLA and MDIS data. For each crater, we determine the depth from MLA as described by the equation in Fig. 1. The diameter is measured by fitting a circle using least squares to points selected by hand that outline the rim of observed craters in the MDIS images. The errors in the circle fit provide an uncertainty in the diameter obtained and capture any associated lack of circularity that most natural craters possess as a consequence of either impact angle effects or the influence of pre-existing target structures. In the case of simple craters $(D<12 \mathrm{~km})$, we used only profiles that passed as close as possible to their center. Any offsets tend to give the craters a shallower appearance. If such an offset was suspected, mainly due to registration problems, it is indicated in our results (Section 3).

The MDIS images were essential for assessing the degradation state of each crater. Craters were grouped into five classes 


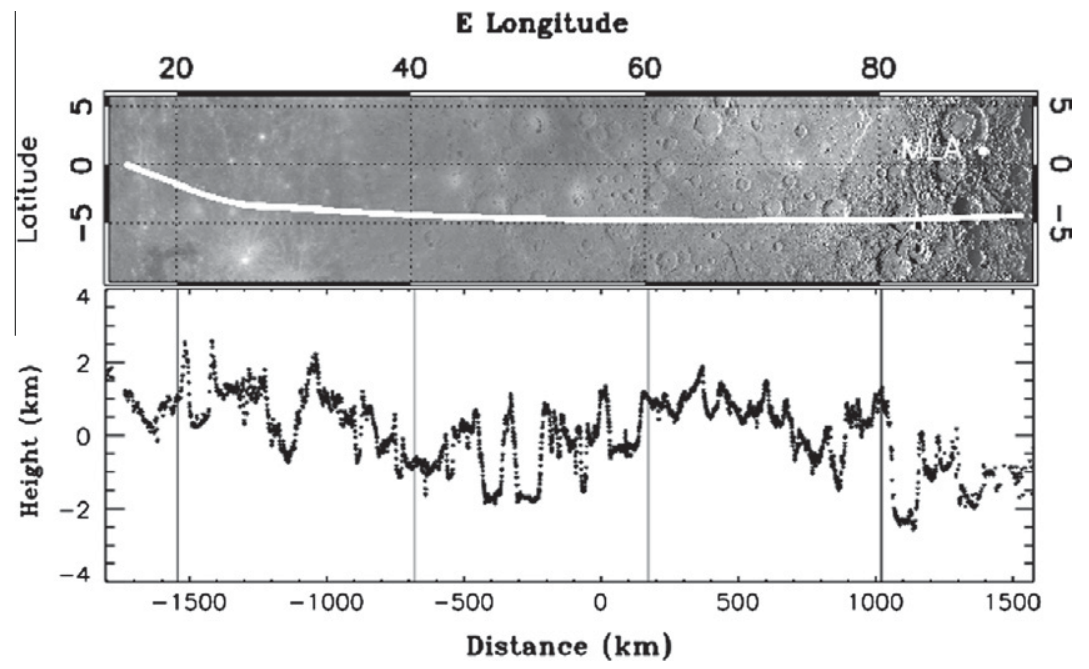

Fig. 3. Location of the MLA footprints (top) and heights (bottom) measured during the first MESSENGER flyby of Mercury. The image mosaic is composed of data obtained during the second and third flybys of Mercury by the MDIS instrument.

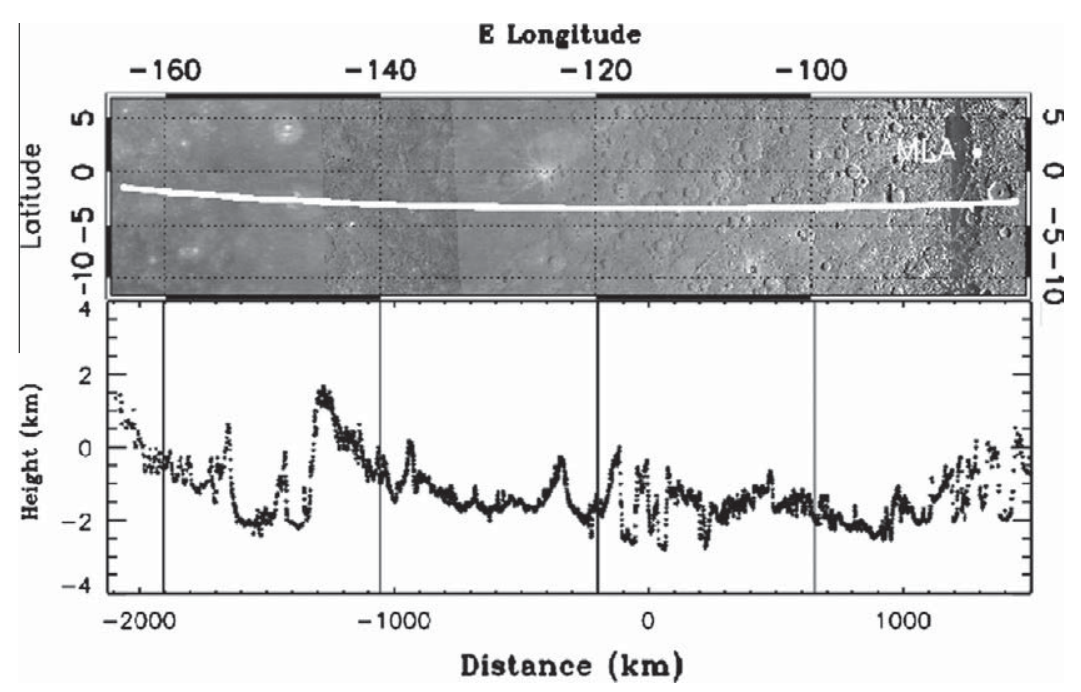

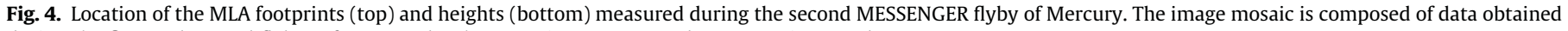
during the first and second flybys of Mercury by the MDIS instrument, and some Mariner 10 data.

following the well-established criteria of Trask (see McCauley et al., 1981; Spudis and Prosser, 1984; Spudis and Guest, 1988). Class 5 are the freshest, while Class 1 features are barely recognizable as craters. Fig. 6 provides examples from MDIS and extensive descriptions of each crater degradation class that guided our analyses. The degradation states of some of the craters measured were difficult to discern because of the high solar incidence angle. This also had been a difficulty for craters analyzed with Mariner 10 data (Spudis and Guest, 1988).

\subsection{Shadow-length measurements}

Depths of craters on Mercury were also estimated by measuring the length of shadows cast by the walls of craters. The length of such a shadow cast inside a crater is defined as the distance in the direction of the Sun separating both at the crater rim and crater floor, the mean pixel value between the sunlit region and the shadow itself. Knowing the Sun angles, and the camera orientation, an estimate of the crater depth can be obtained from this defined shadow length. In this study, we use the well-detailed technique of Chappelow and Sharpton (2002). Unlike the more traditional measurement methods (e.g., Pike, 1988, and references therein), this technique allows one to measure accurate crater depths without being limited to wall shadows that must pass through a crater's center. The Chappelow and Sharpton (2002) technique allows using the outline of the shadows produced within a crater to determine whether a crater is flat-floor, cone-shaped, or parabolic. With this knowledge, the Chappelow and Sharpton (2002) approach provides excellent estimates of the depth of craters when the appropriate equation for depth from shadow length is employed. The approach is most accurate when the shadows within the craters do not completely hide their floors so that the appropriate conic section of revolution (cone or parabola) that describes a crater can be visually confirmed.

This study slightly modifies the Chappelow and Sharpton (2002) method to account for the general viewing geometries encountered by MDIS during the flybys. The original technique of Chappelow and Sharpton (2002) is limited only to data where craters are observed directly overhead, where the emission angle, $e$, defined as the angle between the observed and surface normal is near $0^{\circ}$. The modification corrects the shadow length in the direction of the Sun by using the actual viewing geometry (or emission 

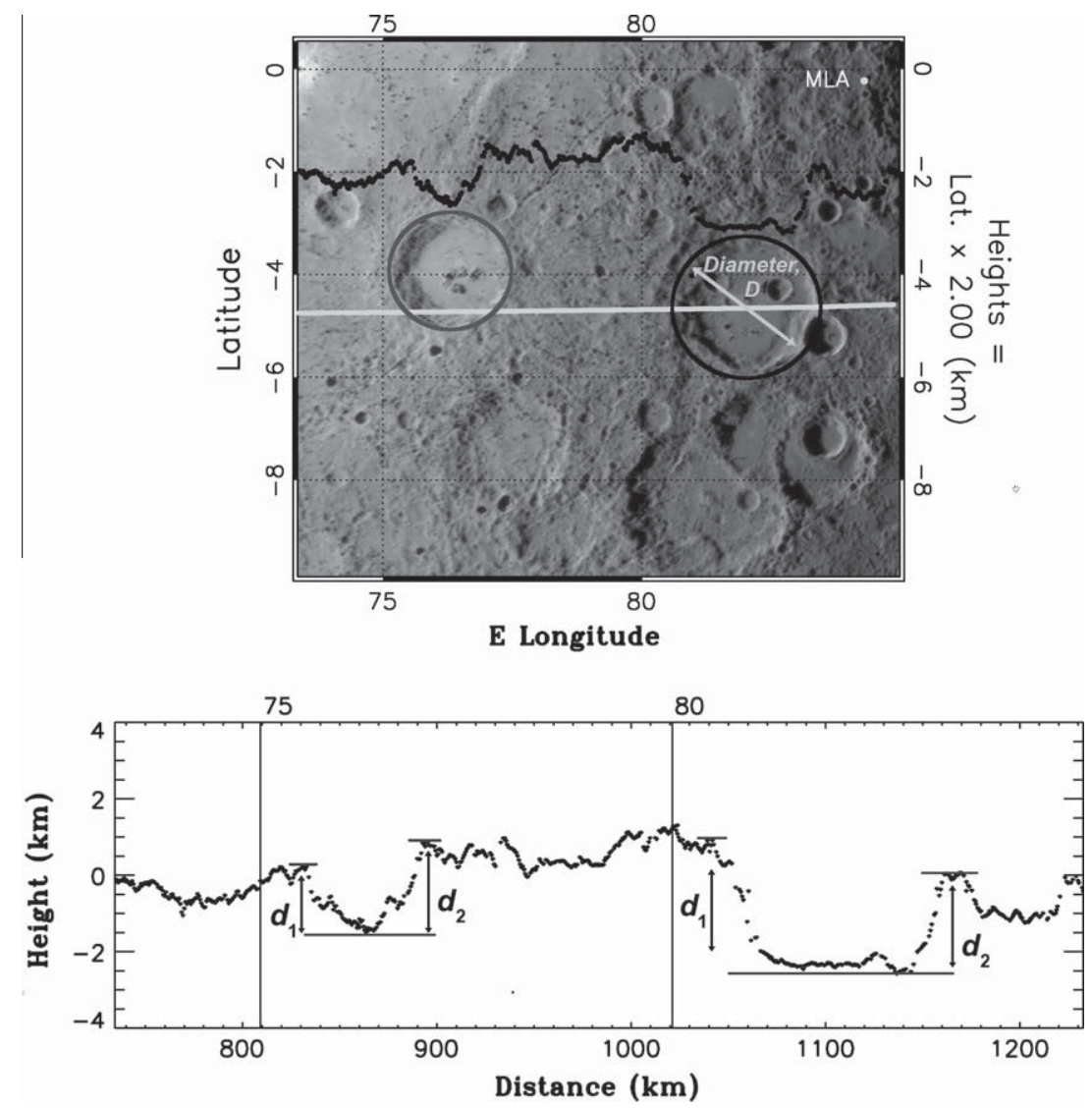

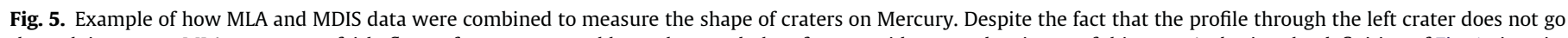

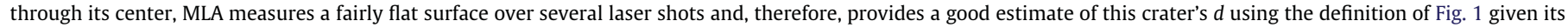
very flat and fresh appearance.

angle, $e$ ) to account for any foreshortening or lengthening of shadows in the direction of the observation (see Appendix A and Fig. $1 \mathrm{~A}$ for further details). The values of $i$ and $e$ employed for this analysis were computed for each pixel within the MDIS images analyzed using the same best spacecraft trajectory, navigation data, and camera distortion model also used to correlate MDIS to MLA data (see Section 2.1).

The requirement that a shadow does not completely hide a crater floor limits the maximum range of solar incidence angles, $i$ used for the measurement of shadows in simple craters to $<80^{\circ}$. Values of $i>80^{\circ}$ usually hide the bottom of simple craters. Larger complex craters with $i>80^{\circ}$ were measured, but only as long as their flatfloor nature could be identified visually, limiting the length of any measured shadow to within the crater floor.

The minimum limit of $i$ considered when measuring shadow lengths was $65^{\circ}$. Experience with data from the Lunar Orbiter Laser Altimeter (LOLA) indicates that fresh lunar crater walls typically possess average wall slopes between $25^{\circ}$ and $30^{\circ}$ relative to the horizontal. Such an angle is equivalent to $60-65^{\circ}$ relative to a surface normal, the angle used to define $i$. The limit that $i$ must be $>65^{\circ}$ thus avoids the mistake of measuring the lengths of shadows from sub-pixel shadows that are the result of sunlight just skimming along the rough surface of these crater walls.

The diameter $D$ for each crater shadow length measured was obtained using the same approach used when $D$ was measured with the MLA-MDIS combination (Section 2.1). The diameter of each crater was determined by fitting via least squares a circle to hand drawn points delineating the rim of each measured crater. The variance in the circle fit usually reflects the natural lack of circularity associated to some degree with all natural impact craters. When measuring craters using both the shadow-length technique and the MLA-MDIS combination, craters that appeared in clusters as likely secondaries were ignored.

As for the crater measurements obtained using MLA, the degradation state of each crater measured was assessed. The same criteria were employed as those discussed in Section 2.1. The degradation class established for many of these crater measured was made fairly easily given the range of $i$ investigated, which are very suitable to assess the morphology of surface features.

In summary, we measured the $d$ and $D$ for simple craters with $65^{\circ}<i<80^{\circ}$, and complex craters with $65^{\circ}<i$ for complex craters. We corrected our results for any $e$ effects that might influence the values of $d$, and kept track of their degradation state. A summary of the number of craters measured in each degradation class is shown in Table 2. Out of a total of 205 craters measured using shadow lengths, 144 craters fell within these $i$ ranges and are all listed in Table 3. Another 38 craters were measured with the combined MDIS-MLA approach and are also listed in Table 3.

\subsubsection{Determining the statistical uncertainties associated with each $d$}

To determine the statistical uncertainties associated with each $d$ measured, the length of a shadow for a given crater in a given image were measured by the same researcher several times, but at disparate occasions. For craters that appeared in multiple images of differing resolutions, a shadow length and consequent $d$ was measured in each image and the resulting variance in $d$ weighted by the resolution of the image. In the case of larger flat-floored craters, $d$ was determined from shadow-lengths cast at several (usually six but sometimes more) locations along a crater wall in 


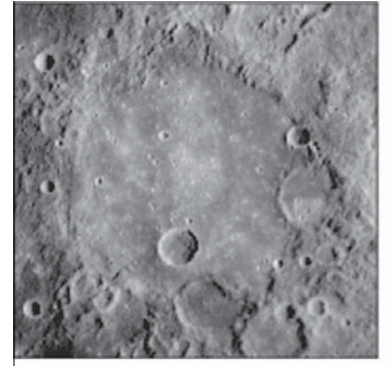

(A)

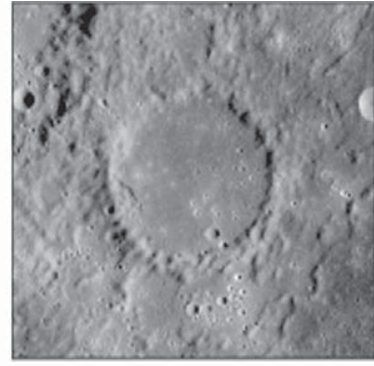

(B)

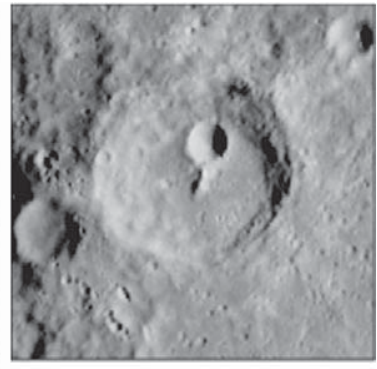

(C)

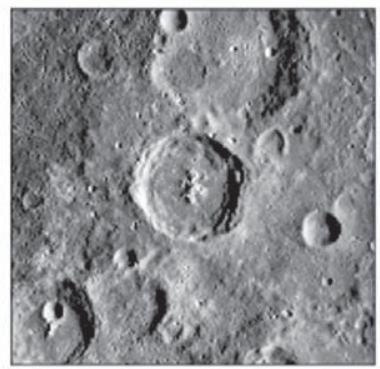

(D)

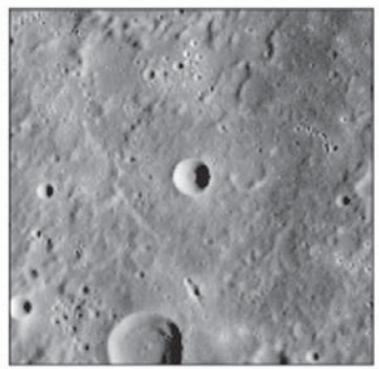

(E)

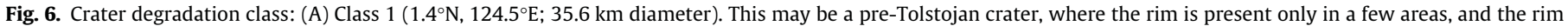

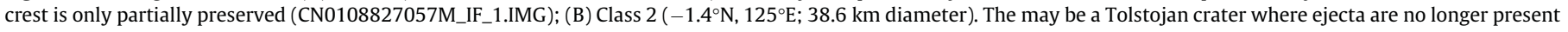

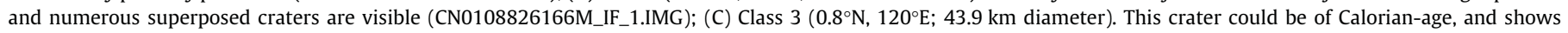

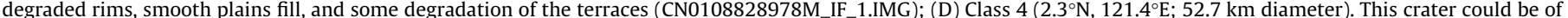

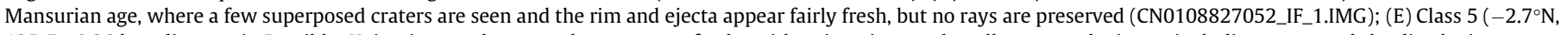

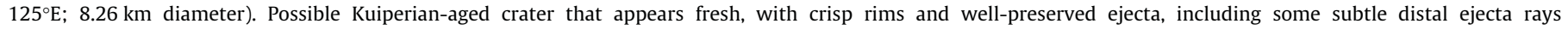
(CN0108826166M_IF_1.IMG). For all craters the dimensions were measured using the MDIS DEM.

Table 2

Summary of craters measured.

\begin{tabular}{lc}
\hline Crater degradation classification or measurement approach & Number \\
\hline Class 5 (freshest) & 23 \\
Class 4 & 75 \\
Class 3 & 58 \\
Class 2 & 13 \\
Class 1 (most degraded) & 2 \\
Classification NA & 11 \\
Depth measured using shadow lengths & 144 \\
Depth measured using MLA & 38 \\
Total analyzed & 182
\end{tabular}

order to obtain the variance in $d$ that are often present in large complex craters.

To minimize any resolution effects on the shadow measurements obtained, no crater was considered with less than 10 pixels across its diameter. In many cases, observed shadows just exceeded half that number. This ensured that $d$ was accurate to at least 25\%. Furthermore, recall that the method of Chappelow and Sharpton (2002) fits a circle or ellipse to the edge of a shadow within a simple crater. In this way, measured shadow lengths do not need to be an integer numbers of pixels in length; shadow length measurements that are fractions of subpixel are possible.

\subsubsection{Evaluating viewing geometry and solar incidence on measured} $d / D$

The measured $d / D$ values were examined as a function of both $e$ and $i$ to verify that the viewing geometry did not affect the measurements obtained. The effect of $e$ on the results for $d / D$ measured is shown in Fig. 7 for two ranges of $e: 0^{\circ}<e<20^{\circ}$ (Fig. 7A) and $20^{\circ}<e<60^{\circ}$ (Fig. 7B). The ranges of $e$ correspond to the two populations of images used in measuring $d$. The large variation in $d / D$ observed within each $e$ range indicates no dependence of $d / D$ on $e$. The absolute difference in the magnitude of $d / D$ seen between the two ranges of $e$ reflects only the resolution of the images used. The best resolutions images were used to measure the smallest craters and had $0^{\circ}<e<20^{\circ}$, while lower resolution images that facilitated measuring larger craters had $20^{\circ}<e<60^{\circ}$. Consequently, the observed larger $d / D$ for $0^{\circ}<e<20^{\circ}$ and smaller $d / D$ for $20^{\circ}<e<60^{\circ}$ is simply a result of the difference in crater sizes measured which are known to become shallower with increasing crater size, especially after the transition to complex morphologies (Pike, 1974) which for Mercury occurs between 10 and $14 \mathrm{~km}$ (Section 1).

A quick analysis of the effects of $i$ on $d / D$ (Fig. 8) might indicate that $d / D$ decreases with increasing $i$ especially when $i>80^{\circ}$. However, when $D$ is considered, it becomes immediately obvious that the observed distribution is truly only a consequence of increasing crater size and not $i$, which are known to become shallower with increasing size (Pike, 1974).

The data obtained for simple craters $(D<12 \mathrm{~km})$ for $i<80^{\circ}$ might be influenced by $i$. While measuring some of these craters it was noticed that shadows cast off crater walls did not have a well-defined crisp edge, but were somewhat diffuse. The slow rise in crater slope and the natural roughness of the floors of these craters near the distal edge of the shadow could lead to this slow brightening of the shadow observed at some small craters. Also, an opposition effect in the crater wall opposite to the shadow, whose slope approaches the normal to the Sun at high $i<80^{\circ}$, might cause a stronger than Lambertian reflection that could shorten any observed shadow lengths seen in especially smaller craters.

These effects do not seem to have a great effect on our measurements and can be absorbed by the observed statistical variances. First, measurements of $d$ for the same crater but at different $i$ shows little difference in the measured value of $d$ and $d / D$. Second, larger craters approaching $D_{t}(10-14 \mathrm{~km})$ dominate the data that appears to shallow with $i$, probably reflecting the expected 
Table 3

Location, dimension and degradation class of craters measured on Mercury.

\begin{tabular}{|c|c|c|c|c|c|}
\hline Crater \# & Longitude & Latitude & Diameter, $D(\mathrm{~km})$ & Depth, $d(\mathrm{~km})$ & Class \\
\hline 102 & 118.22 & -0.74 & $2.07 \pm 0.08$ & $0.34 \pm 0.02$ & 5 \\
\hline 103 & 283.70 & -2.29 & $31.67 \pm 0.26$ & $1.86 \pm 0.20$ & 5 \\
\hline 104 & 287.62 & -1.95 & $10.37 \pm 0.38$ & $0.89 \pm 0.10$ & 3 \\
\hline 106 & 293.02 & -1.87 & $5.90 \pm 0.15$ & $0.97 \pm 0.06$ & 5 \\
\hline 107 & 287.47 & -1.24 & $2.04 \pm 0.05$ & $0.28 \pm 0.01$ & 4 \\
\hline 109 & 290.59 & -0.14 & $3.40 \pm 0.29$ & $0.41 \pm 0.05$ & 5 \\
\hline 110 & 278.01 & 38.29 & $56.62 \pm 0.59$ & $2.85 \pm 0.30$ & 4 \\
\hline 111 & 286.53 & 38.86 & $24.15 \pm 0.80$ & $1.92 \pm 0.41$ & 4 \\
\hline 112 & 288.85 & 39.86 & $17.83 \pm 0.67$ & $2.29 \pm 0.09$ & 4 \\
\hline 114 & 288.36 & 22.81 & $11.50 \pm 0.18$ & $1.09 \pm 0.10$ & 4 \\
\hline 115 & 286.37 & 24.93 & $11.05 \pm 0.20$ & $0.88 \pm 0.04$ & 3 \\
\hline 116 & 285.89 & 26.66 & $6.48 \pm 0.20$ & $0.58 \pm 0.02$ & 3 \\
\hline 117 & 284.70 & 27.21 & $38.10 \pm 0.58$ & $1.66 \pm 0.07$ & 4 \\
\hline 119 & 280.88 & 21.09 & $51.85 \pm 1.14$ & $1.94 \pm 0.20$ & 3 \\
\hline 122 & 279.79 & 12.74 & $15.00 \pm 0.62$ & $1.06 \pm 0.11$ & 4 \\
\hline 123 & 294.99 & 21.78 & $6.53 \pm 0.18$ & $0.60 \pm 0.03$ & 3 \\
\hline 124 & 295.26 & 24.13 & $16.43 \pm 0.19$ & $2.13 \pm 0.25$ & 3 \\
\hline 125 & 291.64 & 23.23 & $28.31 \pm 1.28$ & $2.02 \pm 0.14$ & 3 \\
\hline 126 & 279.40 & 8.83 & $14.34 \pm 0.49$ & $1.19 \pm 0.03$ & 3 \\
\hline 127 & 279.61 & 5.04 & $14.65 \pm 0.27$ & $1.18 \pm 0.03$ & 3 \\
\hline 128 & 282.70 & 4.94 & $32.62 \pm 0.19$ & $1.63 \pm 0.09$ & 4 \\
\hline 129 & 279.14 & 3.54 & $34.93 \pm 0.34$ & $1.41 \pm 0.09$ & 3 \\
\hline 130 & 281.80 & -2.98 & $24.92 \pm 0.40$ & $2.20 \pm 0.31$ & 4 \\
\hline 131 & 284.90 & -4.23 & $51.08 \pm 1.84$ & $1.13 \pm 0.18$ & 3 \\
\hline 132 & 278.05 & -5.64 & $45.00 \pm 1.23$ & $1.61 \pm 0.16$ & 3 \\
\hline 139 & 285.37 & 14.44 & $7.76 \pm 0.22$ & $0.77 \pm 0.06$ & 4 \\
\hline 142 & 292.33 & 2.41 & $5.01 \pm 0.11$ & $0.61 \pm 0.02$ & 4 \\
\hline 143 & 286.69 & 7.51 & $8.24 \pm 0.11$ & $0.74 \pm 0.02$ & 4 \\
\hline 144 & 285.52 & 7.88 & $4.57 \pm 0.25$ & $0.58 \pm 0.04$ & 4 \\
\hline 145 & 292.74 & 9.86 & $5.22 \pm 0.16$ & $0.60 \pm 0.03$ & 3 \\
\hline 146 & 285.55 & 7.21 & $5.91 \pm 0.09$ & $0.49 \pm 0.01$ & 3 \\
\hline 147 & 278.00 & 0.20 & $30.08 \pm 0.25$ & $0.65 \pm 0.13$ & 3 \\
\hline 152 & 290.20 & -0.50 & $16.46 \pm 0.47$ & $1.00 \pm 0.16$ & 4 \\
\hline 153 & 288.30 & 4.25 & $26.66 \pm 1.25$ & $1.12 \pm 0.40$ & 4 \\
\hline 154 & 80.00 & -6.75 & $28.78 \pm 0.70$ & $1.37 \pm 0.14$ & 2 \\
\hline 156 & 74.50 & -6.80 & $12.56 \pm 0.93$ & $1.45 \pm 0.07$ & 4 \\
\hline 158 & 116.80 & -1.00 & $10.78 \pm 0.48$ & $1.77 \pm 0.11$ & 4 \\
\hline 159 & 288.00 & -3.50 & $38.32 \pm 0.82$ & $1.30 \pm 0.06$ & 4 \\
\hline 160 & 284.70 & -2.50 & $3.13 \pm 0.12$ & $0.38 \pm 0.02$ & 3 \\
\hline 161 & 280.50 & 0.50 & $18.52 \pm 0.99$ & $0.64 \pm 0.07$ & 3 \\
\hline 162 & 283.00 & 3.20 & $15.90 \pm 0.00$ & $1.15 \pm 0.06$ & 4 \\
\hline 163 & 279.80 & -1.40 & $11.25 \pm 0.19$ & $0.73 \pm 0.05$ & 4 \\
\hline 164 & 283.40 & 0.25 & $5.46 \pm 0.07$ & $0.53 \pm 0.02$ & 3 \\
\hline 166 & 287.00 & 7.60 & $12.84 \pm 0.13$ & $0.99 \pm 0.09$ & 4 \\
\hline 167 & 262.50 & -5.00 & $23.17 \pm 0.64$ & $1.73 \pm 0.15$ & 4 \\
\hline 168 & 287.15 & 10.30 & $9.21 \pm 0.16$ & $0.73 \pm 0.07$ & 4 \\
\hline 169 & 261.40 & -8.70 & $37.79 \pm 0.93$ & $2.26 \pm 0.22$ & 4 \\
\hline 202 & 113.95 & -9.81 & $1.24 \pm 0.08$ & $0.20 \pm 0.02$ & NA \\
\hline 203 & 113.85 & -9.77 & $1.30 \pm 0.10$ & $0.21 \pm 0.02$ & NA \\
\hline 205 & 112.94 & -9.71 & $2.07 \pm 0.09$ & $0.31 \pm 0.03$ & 4 \\
\hline 206 & 107.40 & -9.66 & $2.76 \pm 0.22$ & $0.31 \pm 0.03$ & 3 \\
\hline 207 & 115.84 & -9.62 & $1.54 \pm 0.10$ & $0.32 \pm 0.04$ & 5 \\
\hline 208 & 106.95 & -9.60 & $2.38 \pm 0.03$ & $0.24 \pm 0.02$ & 4 \\
\hline 210 & 114.13 & -9.55 & $1.39 \pm 0.09$ & $0.22 \pm 0.03$ & 4 \\
\hline 211 & 115.86 & -9.51 & $1.72 \pm 0.03$ & $0.32 \pm 0.03$ & 5 \\
\hline 212 & 118.76 & -9.48 & $2.00 \pm 0.04$ & $0.39 \pm 0.04$ & 5 \\
\hline 213 & 115.87 & -9.46 & $1.95 \pm 0.04$ & $0.32 \pm 0.03$ & 3 \\
\hline 214 & 117.19 & -9.42 & $1.40 \pm 0.03$ & $0.26 \pm 0.03$ & 4 \\
\hline 215 & 117.65 & -9.42 & $2.53 \pm 0.05$ & $0.44 \pm 0.03$ & 3 \\
\hline 216 & 107.74 & -9.42 & $2.83 \pm 0.10$ & $0.38 \pm 0.04$ & 3 \\
\hline 217 & 115.81 & -9.39 & $4.23 \pm 0.04$ & $0.85 \pm 0.04$ & 5 \\
\hline 218 & 116.61 & -9.36 & $1.28 \pm 0.04$ & $0.26 \pm 0.03$ & 4 \\
\hline 219 & 117.22 & -9.37 & $1.25 \pm 0.03$ & $0.26 \pm 0.04$ & 5 \\
\hline 220 & 116.09 & -9.28 & $1.07 \pm 0.04$ & $0.19 \pm 0.04$ & 5 \\
\hline 221 & 116.60 & -9.10 & $1.27 \pm 0.02$ & $0.21 \pm 0.03$ & 5 \\
\hline 222 & 107.03 & -9.09 & $2.43 \pm 0.15$ & $0.27 \pm 0.03$ & 3 \\
\hline 223 & 113.97 & -9.10 & $3.98 \pm 0.04$ & $0.70 \pm 0.04$ & 4 \\
\hline 224 & 118.13 & -9.08 & $1.46 \pm 0.01$ & $0.30 \pm 0.03$ & 4 \\
\hline 225 & 119.03 & -8.98 & $7.50 \pm 0.16$ & $1.58 \pm 0.08$ & 3 \\
\hline 227 & 117.92 & -8.98 & $1.49 \pm 0.03$ & $0.29 \pm 0.03$ & 5 \\
\hline 229 & 112.93 & -8.93 & $2.05 \pm 0.05$ & $0.35 \pm 0.03$ & 3 \\
\hline 230 & 117.02 & -8.89 & $1.00 \pm 0.04$ & $0.19 \pm 0.03$ & 5 \\
\hline 232 & 116.97 & -8.85 & $1.54 \pm 0.06$ & $0.31 \pm 0.04$ & 5 \\
\hline 234 & 115.98 & -8.75 & $3.18 \pm 0.09$ & $0.50 \pm 0.03$ & 2 \\
\hline
\end{tabular}


Table 3 (continued)

\begin{tabular}{|c|c|c|c|c|c|}
\hline Crater \# & Longitude & Latitude & Diameter, $D(\mathrm{~km})$ & Depth, $d(\mathrm{~km})$ & Class \\
\hline 235 & 107.39 & -8.70 & $7.11 \pm 0.06$ & $1.32 \pm 0.08$ & 5 \\
\hline 236 & 115.07 & -8.73 & $1.95 \pm 0.04$ & $0.32 \pm 0.01$ & 4 \\
\hline 238 & 105.54 & -8.60 & $2.85 \pm 0.05$ & $0.32 \pm 0.02$ & 4 \\
\hline 239 & 118.41 & -8.58 & $1.48 \pm 0.01$ & $0.25 \pm 0.02$ & 3 \\
\hline 241 & 114.66 & -8.52 & $2.01 \pm 0.10$ & $0.32 \pm 0.03$ & 3 \\
\hline 242 & 119.07 & -8.52 & $1.33 \pm 0.01$ & $0.24 \pm 0.03$ & 2 \\
\hline 244 & 113.12 & -8.50 & $1.07 \pm 0.10$ & $0.15 \pm 0.03$ & 4 \\
\hline 245 & 114.22 & -8.51 & $1.06 \pm 0.07$ & $0.19 \pm 0.02$ & NA \\
\hline 247 & 108.36 & -8.47 & $7.51 \pm 0.06$ & $1.02 \pm 0.04$ & 3 \\
\hline 248 & 108.59 & -8.40 & $4.23 \pm 0.09$ & $0.57 \pm 0.01$ & 3 \\
\hline 249 & 119.42 & -8.41 & $3.25 \pm 0.10$ & $0.57 \pm 0.05$ & 3 \\
\hline 250 & 113.59 & -8.40 & $1.05 \pm 0.10$ & $0.13 \pm 0.02$ & 4 \\
\hline 251 & 108.52 & -8.39 & $1.99 \pm 0.16$ & $0.23 \pm 0.03$ & 3 \\
\hline 253 & 113.60 & -8.26 & $1.69 \pm 0.05$ & $0.25 \pm 0.03$ & 3 \\
\hline 254 & 115.31 & -8.28 & $0.98 \pm 0.02$ & $0.16 \pm 0.03$ & 5 \\
\hline 257 & 109.80 & -8.21 & $2.98 \pm 0.15$ & $0.35 \pm 0.04$ & 4 \\
\hline 259 & 109.80 & -8.21 & $3.20 \pm 0.04$ & $0.47 \pm 0.02$ & 4 \\
\hline 261 & 112.41 & -8.09 & $1.50 \pm 0.07$ & $0.19 \pm 0.01$ & 4 \\
\hline 262 & 118.64 & -8.06 & $1.46 \pm 0.03$ & $0.28 \pm 0.01$ & 5 \\
\hline 263 & 111.95 & -8.05 & $2.84 \pm 0.07$ & $0.45 \pm 0.05$ & 3 \\
\hline 264 & 108.19 & -8.03 & $1.82 \pm 0.17$ & $0.19 \pm 0.03$ & 3 \\
\hline 265 & 109.61 & -8.02 & $2.52 \pm 0.30$ & $0.34 \pm 0.04$ & 4 \\
\hline 266 & 114.69 & -8.00 & $3.44 \pm 0.04$ & $0.49 \pm 0.04$ & 3 \\
\hline 267 & 114.62 & -7.99 & $1.16 \pm 0.05$ & $0.17 \pm 0.03$ & 4 \\
\hline 269 & 114.84 & -7.93 & $2.08 \pm 0.02$ & $0.32 \pm 0.04$ & 4 \\
\hline 270 & 118.55 & -7.89 & $3.14 \pm 0.08$ & $0.52 \pm 0.07$ & 3 \\
\hline 271 & 114.43 & -7.87 & $3.43 \pm 0.11$ & $0.45 \pm 0.02$ & 4 \\
\hline 272 & 114.79 & -7.80 & $2.99 \pm 0.03$ & $0.50 \pm 0.04$ & 4 \\
\hline 273 & 117.20 & -7.80 & $1.92 \pm 0.04$ & $0.36 \pm 0.04$ & 5 \\
\hline 278 & 107.61 & -7.70 & $3.98 \pm 0.06$ & $0.33 \pm 0.05$ & 4 \\
\hline 279 & 110.50 & -7.62 & $1.97 \pm 0.04$ & $0.31 \pm 0.01$ & 4 \\
\hline 280 & 106.97 & -7.59 & $1.60 \pm 0.06$ & $0.20 \pm 0.01$ & 4 \\
\hline 281 & 110.11 & -7.53 & $1.99 \pm 0.10$ & $0.32 \pm 0.03$ & 3 \\
\hline 282 & 105.67 & -7.50 & $1.84 \pm 0.14$ & $0.22 \pm 0.02$ & 4 \\
\hline 283 & 112.22 & -7.46 & $1.57 \pm 0.03$ & $0.23 \pm 0.01$ & 4 \\
\hline 284 & 112.54 & -7.41 & $1.63 \pm 0.06$ & $0.24 \pm 0.01$ & 4 \\
\hline 285 & 115.06 & -7.34 & $1.81 \pm 0.04$ & $0.29 \pm 0.01$ & 4 \\
\hline 286 & 109.61 & -7.30 & $1.45 \pm 0.05$ & $0.17 \pm 0.03$ & 4 \\
\hline 287 & 109.34 & -7.27 & $2.89 \pm 0.05$ & $0.41 \pm 0.04$ & 4 \\
\hline 288 & 111.23 & -7.20 & $2.65 \pm 0.06$ & $0.48 \pm 0.04$ & 3 \\
\hline 289 & 113.83 & -7.21 & $2.33 \pm 0.01$ & $0.44 \pm 0.05$ & 5 \\
\hline 290 & 109.88 & -7.08 & $3.43 \pm 0.05$ & $0.45 \pm 0.04$ & 4 \\
\hline 292 & 105.90 & -7.03 & $2.41 \pm 0.19$ & $0.26 \pm 0.03$ & 4 \\
\hline 293 & 109.49 & -7.00 & $5.44 \pm 0.14$ & $0.95 \pm 0.10$ & 5 \\
\hline 294 & 110.40 & -6.93 & $2.17 \pm 0.05$ & $0.37 \pm 0.04$ & 4 \\
\hline 295 & 111.87 & -6.75 & $1.49 \pm 0.09$ & $0.23 \pm 0.03$ & 4 \\
\hline 296 & 106.99 & -6.71 & $2.97 \pm 0.05$ & $0.40 \pm 0.03$ & 3 \\
\hline 297 & 110.47 & -6.64 & $1.34 \pm 0.07$ & $0.19 \pm 0.04$ & 4 \\
\hline 298 & 108.13 & -6.66 & $1.78 \pm 0.04$ & $0.20 \pm 0.02$ & 4 \\
\hline 299 & 113.63 & -6.64 & $2.25 \pm 0.04$ & $0.43 \pm 0.03$ & 4 \\
\hline 300 & 110.58 & -6.61 & $2.79 \pm 0.04$ & $0.50 \pm 0.05$ & 3 \\
\hline 301 & 108.95 & -6.49 & $2.33 \pm 0.10$ & $0.33 \pm 0.03$ & 4 \\
\hline 302 & 108.72 & -6.42 & $2.39 \pm 0.13$ & $0.46 \pm 0.06$ & 3 \\
\hline 303 & 108.03 & -6.18 & $5.08 \pm 0.06$ & $0.71 \pm 0.06$ & 3 \\
\hline 305 & 113.12 & -6.06 & $1.08 \pm 0.06$ & $0.21 \pm 0.03$ & 5 \\
\hline 306 & 113.39 & -6.03 & $1.24 \pm 0.08$ & $0.21 \pm 0.03$ & 5 \\
\hline 307 & 107.34 & -6.01 & $4.36 \pm 0.07$ & $0.56 \pm 0.04$ & 3 \\
\hline 308 & 113.64 & -6.02 & $1.85 \pm 0.07$ & $0.35 \pm 0.05$ & 4 \\
\hline 310 & 109.87 & -5.20 & $1.68 \pm 0.09$ & $0.28 \pm 0.04$ & 4 \\
\hline 311 & 109.32 & -5.04 & $2.16 \pm 0.02$ & $0.27 \pm 0.03$ & 4 \\
\hline 312 & 108.03 & -4.81 & $2.70 \pm 0.07$ & $0.38 \pm 0.03$ & 3 \\
\hline 313 & 108.37 & -4.77 & $2.23 \pm 0.03$ & $0.26 \pm 0.02$ & 4 \\
\hline 314 & 107.91 & -4.60 & $2.04 \pm 0.06$ & $0.25 \pm 0.02$ & 3 \\
\hline 315 & 107.89 & -4.29 & $2.20 \pm 0.07$ & $0.34 \pm 0.03$ & 4 \\
\hline 316 & 108.83 & -4.15 & $6.05 \pm 0.08$ & $0.87 \pm 0.06$ & 3 \\
\hline 317 & 108.42 & -3.92 & $2.46 \pm 0.14$ & $0.34 \pm 0.03$ & 3 \\
\hline 318 & 108.17 & -3.89 & $3.52 \pm 0.10$ & $0.50 \pm 0.04$ & 5 \\
\hline 319 & 109.90 & -3.85 & $2.45 \pm 0.11$ & $0.34 \pm 0.02$ & 4 \\
\hline 320 & 108.48 & -3.48 & $3.39 \pm 0.13$ & $0.46 \pm 0.04$ & 3 \\
\hline 321 & 107.52 & -2.60 & $8.73 \pm 0.11$ & $1.31 \pm 0.07$ & 3 \\
\hline mla1-crater1 & 22.00 & -3.00 & $76.20 \pm 10.85$ & $1.56 \pm 0.25$ & 2 \\
\hline mla1-crater2 & 38.00 & 4.00 & $29.44 \pm 4.23$ & $1.36 \pm 0.48$ & NA \\
\hline mla1-crater3 & 68.50 & -5.22 & $5.13 \pm 0.93$ & $0.28 \pm 0.08$ & 3 \\
\hline mla1-crater4 & 72.00 & -5.40 & $5.39 \pm 0.97$ & $0.41 \pm 0.24$ & NA \\
\hline mla1-crater6 & 87.67 & -3.89 & $111.01 \pm 13.98$ & $0.43 \pm 0.02$ & 2 \\
\hline
\end{tabular}


Table 3 (continued)

\begin{tabular}{|c|c|c|c|c|c|}
\hline Crater \# & Longitude & Latitude & Diameter, $D(\mathrm{~km})$ & Depth, $d(\mathrm{~km})$ & Class \\
\hline mla1-crater7 & 89.99 & -4.49 & $23.34 \pm 3.19$ & $1.21 \pm 0.06$ & 2 \\
\hline mla1-crater8 & 86.75 & -4.80 & $7.10 \pm 1.07$ & $0.39 \pm 0.14$ & NA \\
\hline mla1-crater9 & 36.00 & -4.00 & $41.23 \pm 6.96$ & $1.66 \pm 0.02$ & NA \\
\hline mla1-crater10 & 76.00 & -5.00 & $89.90 \pm 11.10$ & $1.96 \pm 0.43$ & 4 \\
\hline mla1-crater11 & 50.00 & -4.00 & $125.65 \pm 17.79$ & $2.71 \pm 0.08$ & 4 \\
\hline mla1-crater12 & 43.00 & -4.00 & $27.25 \pm 3.34$ & $1.29 \pm 0.14$ & 1 \\
\hline mla1-crater13 & 47.00 & -4.00 & $129.63 \pm 16.32$ & $2.30 \pm 0.12$ & 3 \\
\hline mla1-crater16 & 35.00 & -4.00 & $34.37 \pm 5.52$ & $1.73 \pm 0.31$ & 4 \\
\hline mla1-crater 17 & 38.00 & 4.00 & $32.24 \pm 5.86$ & $1.36 \pm 0.47$ & 3 \\
\hline mla1-crater18 & 41.00 & 4.20 & $11.94 \pm 1.82$ & $0.94 \pm 0.07$ & 4 \\
\hline mla1-crater19 & 44.00 & 4.00 & $9.02 \pm 1.39$ & $0.63 \pm 0.05$ & 3 \\
\hline mla1-crater20 & 53.80 & -4.80 & $8.30 \pm 1.36$ & $0.96 \pm 0.36$ & 4 \\
\hline mla1-crater22 & 125.02 & -8.88 & $31.83 \pm 3.60$ & $1.73 \pm 0.15$ & 2 \\
\hline mla1-crater23 & 60.85 & -4.70 & $3.53 \pm 0.64$ & $0.46 \pm 0.02$ & 4 \\
\hline m2-crater1 & 229.70 & -3.98 & $23.76 \pm 3.99$ & $0.50 \pm 0.04$ & NA \\
\hline $\mathrm{m} 2$-crater 2 & 239.70 & -3.30 & $16.84 \pm 2.37$ & $0.84 \pm 0.04$ & 2 \\
\hline $\mathrm{m} 2$-crater3 & 240.50 & -3.60 & $9.90 \pm 1.58$ & $0.32 \pm 0.06$ & NA \\
\hline $\mathrm{m} 2$-crater 4 & 241.87 & -4.05 & $76.34 \pm 7.79$ & $2.31 \pm 0.40$ & 4 \\
\hline m2-crater5 & 244.40 & -3.63 & $76.17 \pm 9.47$ & $1.90 \pm 0.04$ & 2 \\
\hline $\mathrm{m} 2$-crater6 & 244.89 & -3.94 & $41.58 \pm 4.59$ & $1.87 \pm 0.52$ & 4 \\
\hline m2-crater7 & 248.45 & -3.96 & $17.91 \pm 2.38$ & $1.06 \pm 0.27$ & 3 \\
\hline m2-crater8 & 257.91 & -3.31 & $15.54 \pm 2.17$ & $0.55 \pm 0.14$ & 2 \\
\hline m2-crater8a & 251.43 & -3.42 & $3.13 \pm 0.54$ & $0.22 \pm 0.01$ & 4 \\
\hline m2-crater9 & 261.37 & -3.62 & $9.23 \pm 1.25$ & $0.24 \pm 0.00$ & 3 \\
\hline m2-crater10 & 263.98 & -3.44 & $3.45 \pm 0.62$ & $0.29 \pm 0.00$ & 3 \\
\hline m2-crater11 & 266.49 & -3.18 & $17.31 \pm 2.54$ & $0.66 \pm 0.25$ & 2 \\
\hline m2-crater12 & 272.14 & -3.15 & $29.46 \pm 4.85$ & $0.33 \pm 0.06$ & 2 \\
\hline m2-crater13 & 272.63 & -3.60 & $26.08 \pm 3.45$ & $1.47 \pm 0.08$ & 3 \\
\hline m2-crater14 & 273.16 & -3.55 & $34.56 \pm 4.48$ & $1.44 \pm 0.04$ & 2 \\
\hline m2-crater15 & 273.16 & -3.55 & $3.57 \pm 0.01$ & $0.72 \pm 0.06$ & NA \\
\hline m2-crater16 & 275.31 & -3.06 & $57.07 \pm 3.57$ & $0.81 \pm 0.02$ & 3 \\
\hline m2-crater17 & 277.46 & -2.19 & $101.80 \pm 3.81$ & $0.32 \pm 0.03$ & 3 \\
\hline m2-crater18 & 280.77 & -2.35 & $100.48 \pm 3.55$ & $0.46 \pm 0.02$ & 1 \\
\hline
\end{tabular}
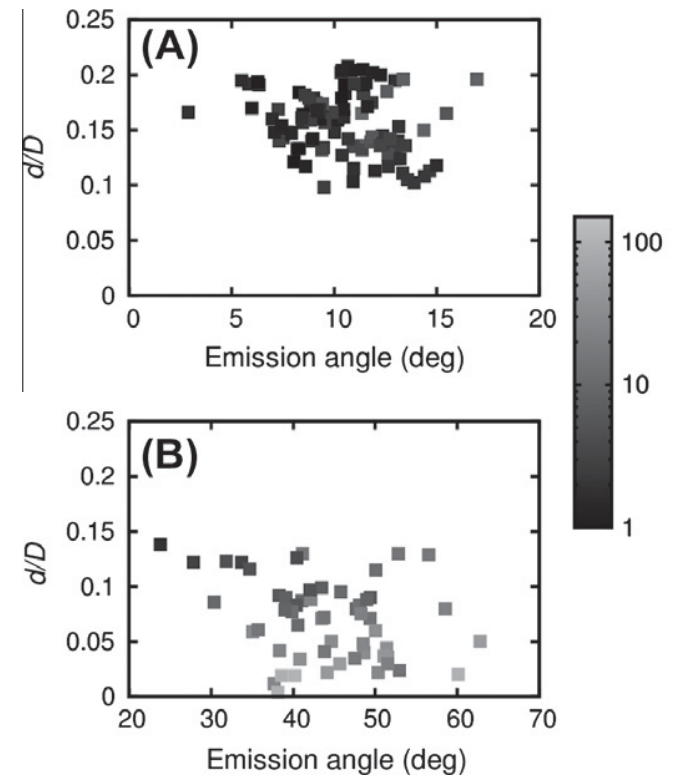

Fig. 7. $d / D$ as a function of emission angle $e$, where $d$ is measured from shadow lengths. Data is shaded by crater diameter. Two sets of image resolutions were used to measure $d / D$ with corresponding values of $e$ between $0-20^{\circ}(\mathrm{A})$, and $20-65^{\circ}((\mathrm{B})$ see text for further detail).

shallowing associated with craters that are on the verge of becoming complex. And third, in many instances, there remains a significant variation of $d / D$ at any $i<80^{\circ}$.

Since Chappelow and Sharpton (2002) and Chappelow (2008) has developed a more versatile shadow length technique that makes no a priori assumption on the shape of the crater. Only an outline of the shadow needs to be fit by an ellipse. A subset of

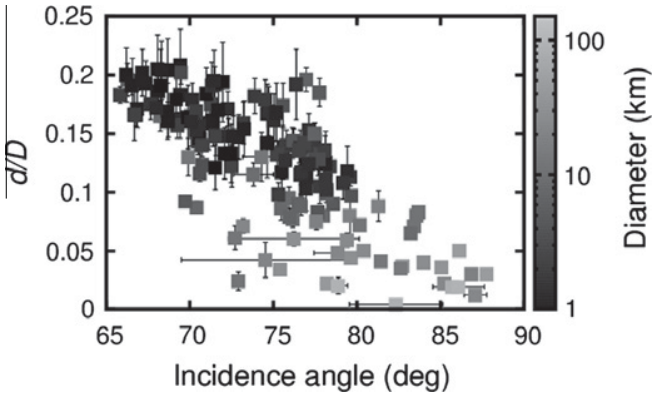

Fig. 8. The depth to diameter ratio $d / D$ as a function of Sun incidence angle $i$, where depth is measured from shadow lengths. Data is shaded by crater diameter. The ratio $d / D$ is not obviously influenced by $i$; most of the difference in $d / D$ can be attributed to the crater diameter and the transition to shallower complex craters.

our data was measured using this second technique, where no correction for $e$ was employed, by utilizing MDIS images with $e$ near $0^{\circ}$. A statistical Cochran paired $t$-test, which evaluates the likelihood that two samples are identical when they possess uneven variances, was used to compare the amount of overlap between the sigma errors generated by the $d$ measurements for each one of the 100 or so craters measured using this second technique with measurements using the first technique. On average the $d$ measurements by both methods are identical with an $87 \%$ level of confidence. Thus, the shadow measurements performed by these two methods can be considered identical and are integrated into the rest of this study.

\subsection{Assessing the shadow length measurements}

For the purpose of assessing the quality of the crater measurements obtained from the various topographic sources, we assume 


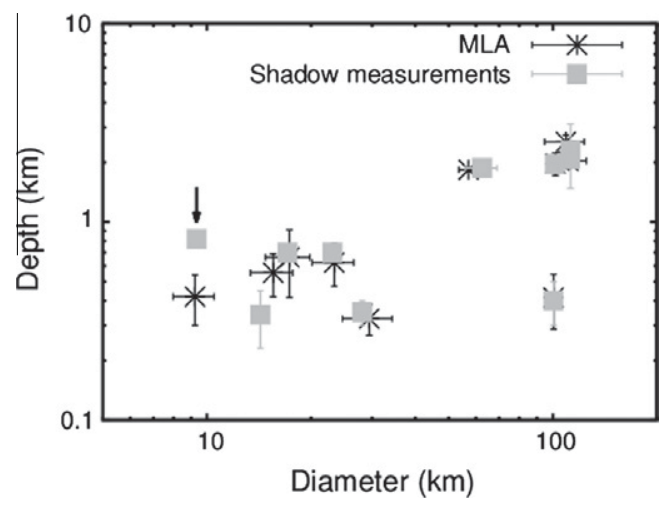

Fig. 9. Evaluation of shadow length technique employed in this study. The comparison of the crater depth $d$ versus diameter $D$ measured using the trusted MLA-MDIS technique relative to measurements of shadow length reveal that both data have a $76 \%$ chance of being identical when using a Cochran paired $t$-test. This percentage chance is increased to $82 \%$ if the one crater indicated (arrow) is not considered. A careful analysis of the location of the MLA track relative to the MDIS images for this latter crater indicates that the MLA footprint did not go through its bottom, leading to the observed shallower depth measured by MLA.

that the measurements collected by combining the MLA with MDIS data are the most accurate. This assumption is justified given that the MLA instrument measures range very accurately $(<1 \mathrm{~m})$ within each of one of its footprints (Zuber et al., 2008). When determining $d$, the MLA measurements possess some uncertainty given that a MLA footprint may not fall exactly on a crater rim or at the very lowest point within a crater. Nevertheless this uncertainty is very small relative to naturally occurring variations in rim heights and crater depth (e.g., Fig. 1) that can yield substantial variance to any measurement of $d$.

Errors in $D$ as measured from MDIS data are also likely to be small. Reprojections of one NAC image on top of another generate small errors in registration that are on the order of a few NAC pixels ( $\sim 50-200 \mathrm{~m}$ depending on the range of the MESSENGER spacecraft to the surface of Mercury). Furthermore, such reprojections overlap well with the most recent control network developed for Mercury using Mariner 10 data (Robinson et al., 1999). Here too, the lack of circularity that exists in most naturally occurring craters leads to variances in measured $D$ that are typically larger than errors obtained from registration problems.

We used the combined MLA-MDIS data to test the first of the shadow length techniques for 10 craters. These 10 craters are the only ones that possess both the lighting conditions suitable for shadow length measurements and MLA transects obtained during the Mercury flybys. As in Section 2.2, a paired Cochran paired $t$-test indicates that the $D$ and $d$ measured using the MLA-MDIS combination and the shadow length techniques are indistinguishable, with an average chance of $82 \%$ of being exactly equal to each other (Fig. 9). In this particular analysis, the Cochran paired $t$-test was used to compare the overlap between $d / D$ and their associated measurement uncertainties for each individual crater investigated using both the MLA-MDIS combination and the shadow-length measurement. Consequently, this study considers all the shadowlength measurements of $d$, and the MDIS derived $D$ as being essentially equivalent to a measurement obtained with the MLA-MDIS approach.

\section{Diameter and depth results}

Results are shown in Fig. 10 for $d$ versus $D$ obtained using just the combined MLA-MDIS data. These data are compared to the results of Pike (1988) using the Mariner 10 data. In most cases, the craters measured by MLA are shallower than those measured by
Pike. The most likely explanation is that most of the craters encountered by MLA were not particularly fresh. This is consistent with the degradation classification of the craters. MDIS images reveal that MLA did not measure a single Class 5 crater, with a crisp appearance, fresh ejecta and rays. The MLA-MDIS data are insufficient to show alone any statistical evidence for differences in the depth of craters with decreasing degradation state. The observed shallowness of the smaller simple bowl shaped craters cannot be attributed to the MLA profile missing the center of these craters, except for the two cases shown in Fig. 10. In all the other cases, within the limitations of the MLA and MDIS data sets obtained during the Mercury flybys, the MLA transects passed through the center of these craters.

When the 38 MLA-MDIS results for crater $d$ and $D$ are combined with the additional 144 craters (Table 3 ) measured using shadow lengths (Fig. 11), the maximum $d$ values measured are well bound by Pike's analysis. No crater observed is deeper than Pike's distribution. In fact, most of the craters measured in this study are shallower than those reported by Pike mainly because Pike did not include degraded craters in his analyses.

When the crater degradation class is considered (Fig. 12), the average value of $d$ for small simple craters decreases slightly with observed degradation class, very much as is assumed in other studies simply from $d / D$ measurements (e.g., Garvin and Frawley, 1998). The data also suggest that degradation reduces $d$ for larger simple craters $(5 \mathrm{~km}<D<12 \mathrm{~km})$ more quickly than for smaller ones. This observation could be explained by the longer time a large simple crater has to be exposed to the Mercury cratering flux before it is considered degraded. The consequence of this longer exposure to reach a given degradation state means that larger craters will have been exposed to a greater number of both large and small impacts. These impacts tend to enhance $D$ while reducing $d$ as rims are eroded and back-wasted, and the crater interior is filled in with rim material (Cintala et al., 1976; Head et al., 1976; Malin and Dzurisin, 1977, 1978; Oberbeck et al., 1977; Spudis and Guest, 1988).

For complex craters $(D \geqslant 12 \mathrm{~km})$, the decrease in $d$ with increasing degradation (decreasing degradation class) is even more obvious than for the small simple craters. While rim erosion and back-wasting over time are probably contributors to the observed decrease in $d$, images (e.g., Fig. 6A and B) indicate that most of the loss in $d$ results from in-filling, often by smooth plains materials. It might also be possible that some of the observed difference is the

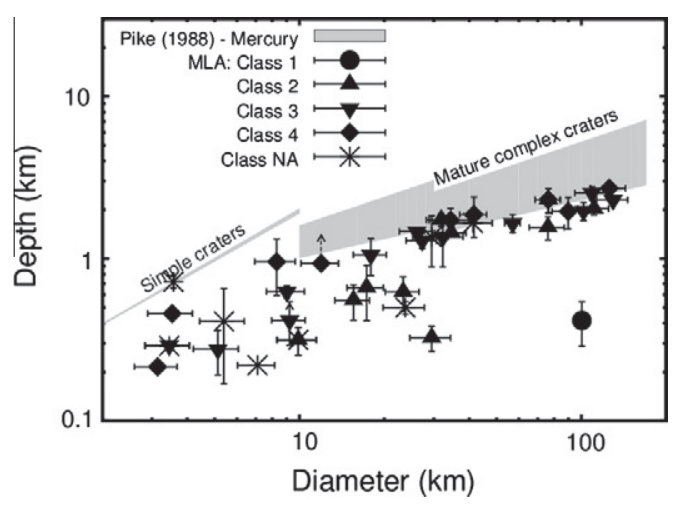

Fig. 10. Crater depth $d$ to diameter $D$ measured by combining MLA altimetry with MDIS imagery. The gray regions span the one sigma error of the fits obtained by Pike (1988) for the depth-to-diameter relation of the freshest craters on Mercury. The crater profiles by MLA craters are split by crater degradation class. Craters classified as '?' did not have sufficient image resolution or the Sun angle was too high to accurately identify the class of the crater at the time when the measurement was made. Two profiles shown with arrows may not have sampled the bottom of the observed crater, probably resulting in shallower depths. 


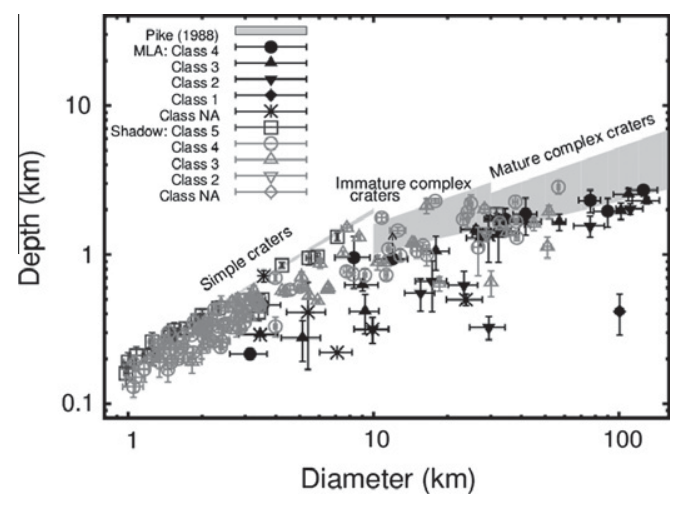

Fig. 11. Crater depth $d$ to diameter $D$ distribution measured using MLA and shadow length measurements for $\sim 180$ craters. Also shown is the measured diameter to depth relationship from Pike (1988) for Mercury. The craters are split by degradation class.

result of isostatic uplift that could exist when comparing craters of differing degradation state. It is not inconceivable that in it's past the crust and lithosphere of Mercury was warmer than in more recent times. As a consequence, the formation of an older complex crater might have encountered a softer target that would have undergone greater isostatic adjustment than a younger and fresher crater, which is more likely to have encountered a colder and stiffer lithosphere.

Other factors could also be influencing the observed distribution of $d / D$ results. It is well known, for example, that target strength plays a role at the late stages of crater growth when excavation is nearly complete and craters collapse (Fulmer and Roberts, 1963; Gault et al., 1968; Shoemaker, 1963; Cintala et al., 1976, 1977; Holsapple, 1993; Barnouin-Jha et al., 2007; Housen and Holsapple, 2011). These strength effects can result in subtle changes in crater morphology that might provide a way to differentiate between targets composed of basalts, fragmented megaregoliths and sediments (Pike, 1980, 1988; Cintala et al., 1976, 1977). A preliminary analysis (Fig. 13) of the $d / D$ ratio for Class 4
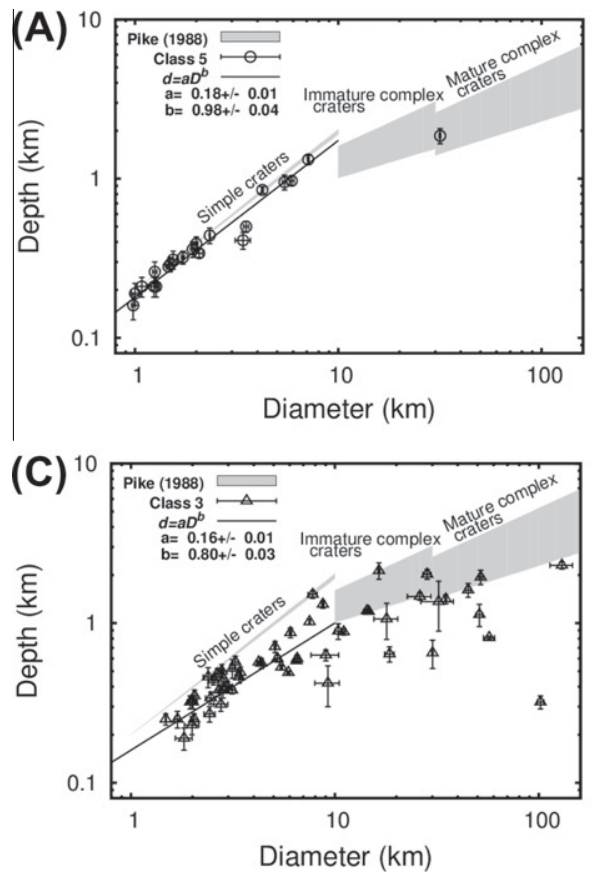

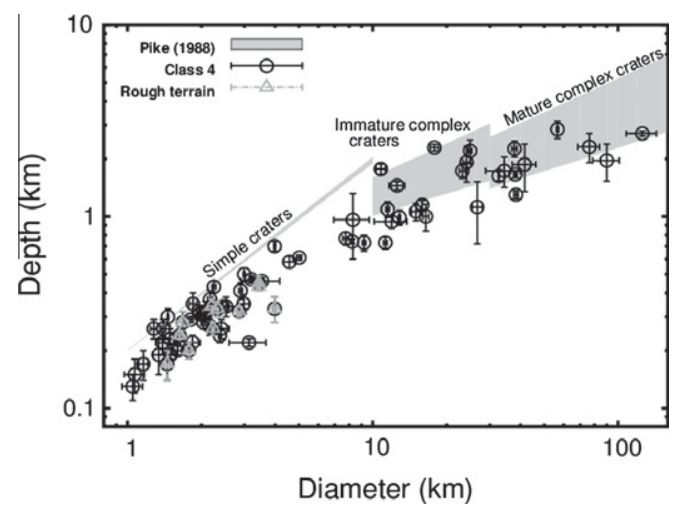

Fig. 13. Crater depth $d$ to diameter $D$ distribution measured using MLA and shadow length measurements for Class 4 craters, highlighting the craters formed in a rough hummocky terrain.

craters formed in a rough, hummocky terrain that might be more battered and thereby weaker relative to other areas on Mercury shows no difference relative to the general population of Class 4 craters measured. This class of crater is fairly fresh, and is present in sufficient numbers in our study for such a quick analysis. However, these Class 4 craters may also be degraded sufficiently that such target effects could be hidden. A better assessment of how target properties influence the morphology of craters will be possible by analyzing orbital data currently being obtained by the MESSENGER spacecraft for very fresh Class 5 craters alone.

As a final observation, our data for 182 craters indicate that many of the features associated with the transition from simple to complex craters, such as onset of terracing and the presence of fairly substantial slumps (e.g., Fig. 14), usually occur at slightly larger diameters than indicated in a final assessment of Mariner data (Pike, 1988). In those studies, $D_{t}$ was found to be $\sim 10 \mathrm{~km}$; here it appears to be closer to $\sim 12 \mathrm{~km}$ but, as with the assessment of target property effects, additional analysis of orbital data will be needed to confirm this result.
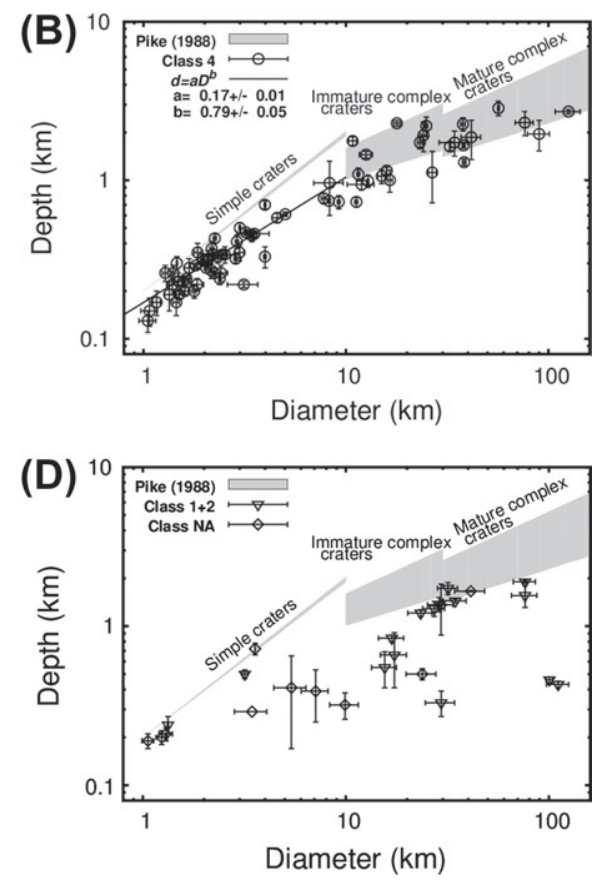

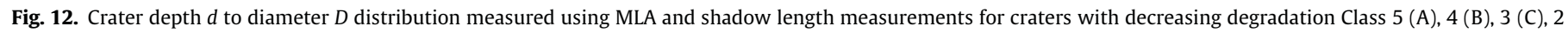
and 1(D). Deepest craters are generally the freshest craters as is typically assumed. 


\section{Conclusions}

The use of MLA and MDIS data collected during the three MESSENGER spacecraft flybys provides an initial view of the $d / D$ relationship for craters on Mercury that can be compared with previous data derived from Mariner 10 . The main results indicate:

1. The depth of small craters that are simple $(<12-\mathrm{km}$ diameter $)$ are well bound by previous observations by Pike (1988), with no crater observed deeper than the distribution presented by Pike. The depth of small fresh (Class 5 ) craters are defined by the power function (in $\mathrm{km}$ ):

$$
d=(0.18 \pm 0.1) D^{(0.98 \pm 0.04)}
$$

while the average population of all simple craters measured on Mercury follow the shallower power function (in $\mathrm{km}$ ):

$$
d=(0.18 \pm 0.1) D^{(0.70 \pm 0.3)}
$$

2. Large complex craters ( $>12 \mathrm{~km}$ diameter) match previous observations reasonably well, falling within the bounds of the Mariner 10 data, especially for fresher (Class 4-5) craters.

3. Consideration of crater degradation shows that in general both simple and complex craters become shallower with increasing degradation state. In the case of large complex craters, the reduction of $d$ is appears to be primarily caused by infilling, often by material that fills many of the intercrater plains units seen in many regions of Mercury (Spudis and Guest, 1988; Denevi et al., 2009). Differences in isostatic adjustment between a very old and younger crater might also be a factor. The reduction in depth of simple craters is apparently the result of subsequent cratering that erodes them.

4. Initial consideration of the effects of target properties on the $d$ / $D$ ratio show no obvious effects, but only slightly degraded, Class 4 craters were available for our analysis. Future efforts will be needed that combine high-resolution MLA data with high-resolution images to more accurately assess other factors that might contribute to the original shape of craters (e.g., target roughness, surface slope, target color properties, radar properties and so on).

5. The observed $D_{t}$ value of $\sim 12 \mathrm{~km}$ is a little larger than the final assessments published on the basis of Mariner 10 observations (Pike, 1988), but additional study is required to confirm this result.

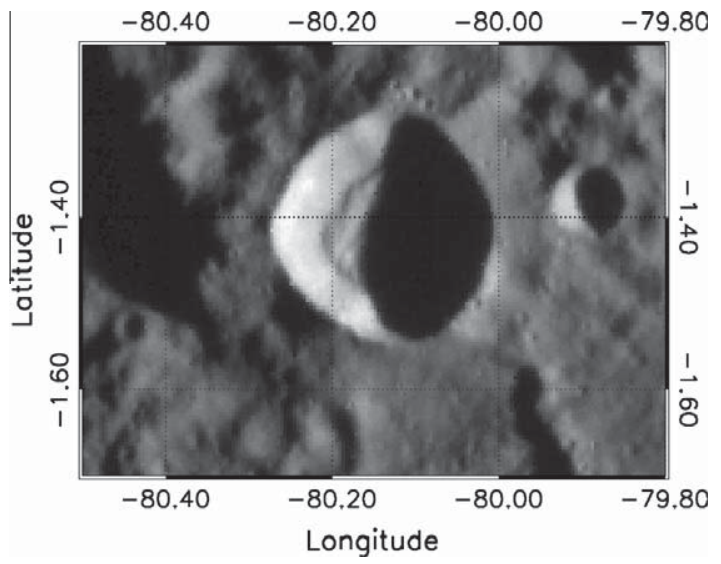

Fig. 14. A Class 4 crater with an $11.3 \pm 0.2 \mathrm{~km}$ diameter that possesses evidence in its interior typically associated with the initial stages of the transition from simple to complex cratering.

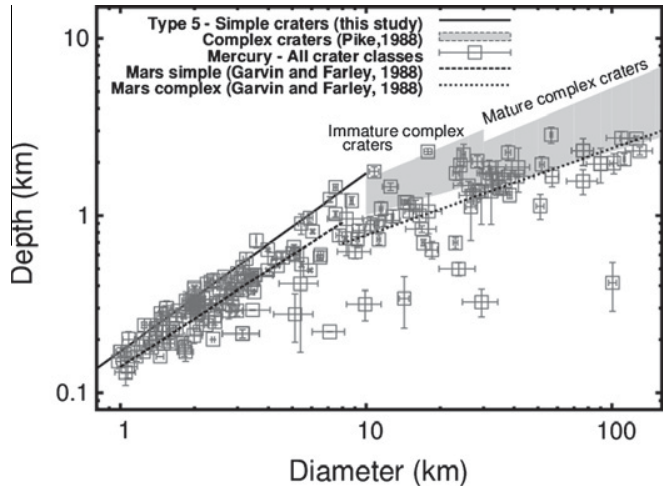

Fig. 15. The depth (gray squares) of all craters measured on Mercury as a function of diameter. Overlain is the fit for simple Class 5 craters measured in this study (solid line), and the fit for fresh simple (long dash) and complex (short dash) craters on Mars measured by Garvin and Frawley (1998). The gray region define immature complex and the mature complex craters measured by Pike (1988).

The result that fresh (Class 5) simple craters are consistent with Pike's analysis and remain significantly deeper than those observed on Mars (see Fig. 15), combined with the probable confirmation that $D_{t}$ remains large on Mercury relative to even the newer values of 7-8 $\mathrm{km}$ for Mars seem to confirm previously held views on the surface properties of Mercury relative to Mars. These views suggest that Mercury's surface is in a qualitative sense stronger than on Mars, allowing for the formation of small fresh craters that are deeper than those on Mercury, more akin to what is observed on the "dry" Moon (Pike, 1980, 1988). Studies focusing on the effects of target strength (Fulmer and Roberts, 1963; Gault et al., 1968; Shoemaker, 1963; Cintala et al., 1976, 1977; Holsapple, 1993; Barnouin-Jha et al., 2007), indicate that an increase in target strength will restrict the amount of crater collapse that occurs immediately following excavation, typically producing deeper small craters that are less likely to become complex craters. The larger value of $D_{t}$ on Mercury versus Mars substantiates the view that Mercury's upper crustal rocks are somewhat stronger than Mars' (Pike, 1980, 1988). Such an interpretation would add credence to the view that rocks are being significantly weakened on Mars due to the wide-spread presence of volatiles, despite the fact that many of the smaller fresh craters on Mars are more likely to have formed in recent times in regions of Mars where significant amounts of volatiles are probably not present (e.g., Bibring et al., 2005). This result is also somewhat surprising given further experimental evidence (Barnouin et al., 2011) confirming that increasing impact velocities reduces $d / D$ of transient craters formed at the end of excavation phase of cratering. Such a reduction in $d / D$ has also been reported before in strong, solid targets, and plausibly in gravitational controlled granular ones (see Schultz, 1988 and references therein). Additional experimental and numerical investigations are required to resolve exactly the consequences of impact velocity on the transient and final crater shape and what it might mean when interpreting observations of craters on Mercury and Mars. It remains clear that the observed difference in $D_{t}$ between Mercury and Mars might still be due in part to the big differences in mean impact velocities expected on these two planets. Additional analysis of Mercury highresolution imaging and MLA data collected during orbit, as well as experimental and theoretical work will be needed to fully resolve how the differences in surface strength and impact velocity at Mercury relative to Mars influences the observed differences in $D_{t}$.

\section{Acknowledgements}

This study was made possible with support from the MESSENGER project funded by the NASA Discovery Program and a grant 

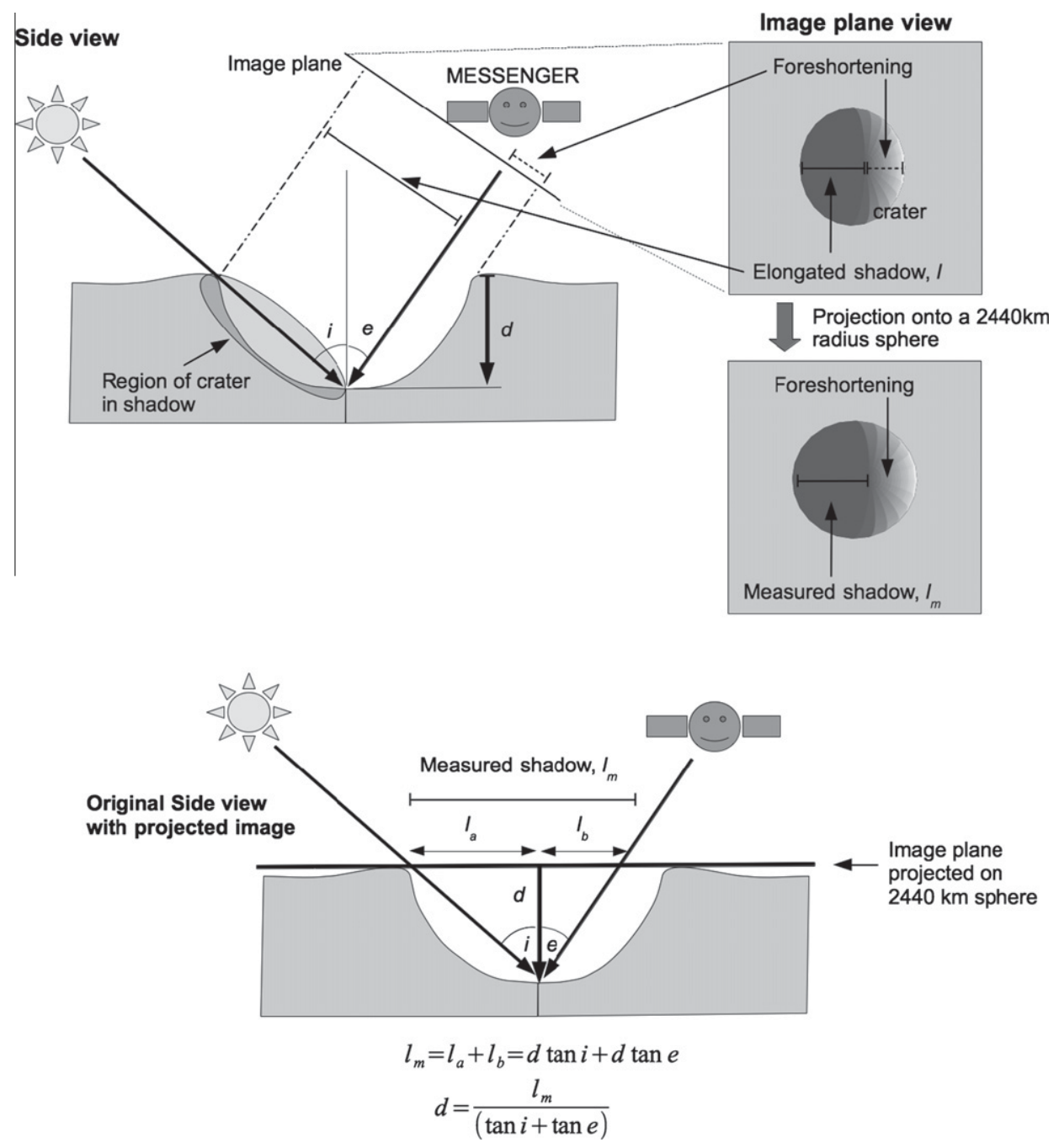

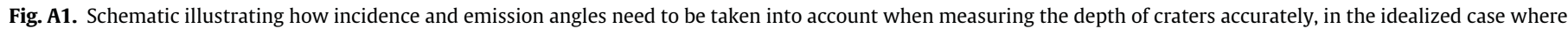
the Sun, crater and viewer are in the same plane.

to R. Herrick from the NASA Planetary Mission Data Analysis Program. We are also grateful to two anonymous reviewers who comments greatly improved the text.

\section{Appendix A}

The original shadow-length formulations derived by Chappelow and Sharpton (2002) that provide estimates of $d$ assume nadir observations where the emission angle, $e$ equals $0^{\circ}$. The MESSENGER MDIS images used in this analysis were rarely obtained in such a viewing geometry. The formulations of Chappelow and Sharpton (2002), therefore, had to be modified for emission angle. Fig. A1 illustrates how this correction was done in the idealized case where the Sun, crater and MDIS are in the same plane. In this instance, the shadow directly crosses the center of the observed crater. In such an instance, a non-zero emission angle results in an observed shadow that is either foreshortened or elongated. After correctly being projected onto a flat sphere with a radius of $2440 \mathrm{~km}$ assumed for Mercury, it is trivial to show that the measured shadow length, $l_{m}$ is given by:

$l_{m}=l_{a} \pm l_{b}=d \tan i \pm d \tan e$

where $l_{a}$ is the length of the shadow due to solar incidence and $l_{b}$ is the length of the shadow enhanced or lost because of emission angle effects. A "+" is used when the spacecraft is looking back at the surface towards the Sun, while a "-" applies for the case where the Sun is behind the spacecraft. The value of $d$ for an observed crater can then be determined from:

$d=\frac{l_{m}}{\tan i \pm \tan e}$

This last formulation was used to replace that described by Chappelow and Sharpton (2002) for the case when a crater has a flat floor. The other two formulations of Chappelow and Sharpton (2002) can be re-written in the following manner by simply replacing the $\tan i$ term with $\tan i \pm \tan e$ :

$d=\frac{D}{4\left(1-l_{m} / D\right)(\tan i \pm \tan e)} \quad$ for a parabolic shaped crater and,

$d=\frac{D}{2\left(1-l_{m} / D\right)(\tan i \pm \tan e)} \quad$ for a conic shaped crater.

In most instances, the Sun, crater and imager were not all aligned in the same plane. For these types of observations, it is trivial to show that to obtain the correct value of $d$, the emission angle term must be further multiplied by the sine of the angle $v$ separating the vertical plane aligning the Sun and the crater and the vertical plane defined by the crater and viewer. The new equations now become: 
$d=\frac{D}{4\left(1-l_{m} / D\right)(\tan i \pm \sin v \tan e)}$ for a parabolic shaped crater and,

$d=\frac{D}{2\left(1-l_{m} / D\right)(\tan i \pm \sin v \tan e)} \quad$ for a conic shaped crater.

\section{References}

Asphaug, E., Moore, J.M., Morrison, D., Benz, W., Nolan, M.C., Sullivan, R.J., 1996 Mechanical and geological effects of impact cratering on Ida. Icarus 120,158 184.

Barnouin, O.S., et al., 2011. Experimental results investigating the impact velocity effects on crater growth and transient crater diameter-to-depth ratio. Lunar Planet. Sci. 42, 2258.

Barnouin-Jha, O.S., Cintala, M.J., Crawford, D.A., 2003. Effects of pre-existing target structure on the formation of large Craters. In: Dressler, B., Kenkmann, T. Schieber, M., Poesges, G. (Eds.), Third International Conference on Large Meteorite Impacts, p. 4106.

Barnouin-Jha, O.S., Cintala, M.J., Crawford, D.A., 2005. Impact into coarse grained spheres. Lunar Planet. Sci. Conf. 36, 1585.

Barnouin-Jha, O.S., Yamamoto, S., Toriumi, T., Sugita, S., Matsui, T., 2007. Nonintrusive measurements of crater growth. Icarus 188, 506-521.

Bibring, J.-P. et al., 2005. Mars surface diversity as revealed by the OMEGA/Mars Express observations. Science 307, 1576-1581.

Boyce, J.M., Garbeil, H., 2007. Geometric relationships of pristine martian complex impact craters, and their implications to Mars geologic history. Geophys. Res. Lett. 34, L16201. doi:10.1029/2007GL029731.

Cavanaugh, J.F. et al., 2007. The Mercury Laser Altimeter instrument for the MESSENGER mission. Space Sci. Rev. 131, 451-479.

Chappelow, J.E., 2008. Determining simple impact crater shapes from shadows. Lunar and Planetary Sci. 39, 1441.

Chappelow, J.E., Sharpton, V.L., 2002. An improved shadow measurement technique for constraining the morphometry of simple impact craters. Meteorit. Planet. Sci. 37, 479-486

Cheng, A.F., Barnouin-Jha, O.S., 1999. Giant craters on Mathilde. Icarus 140, 34-48.

Cintala, M.J., Head, J.W., Mutch, T.A., 1976. Martian crater depth/diameter relationships - Comparison with the Moon and Mercury. Proc. Lunar Planet. Sci. Conf. 7, 3575-3587.

Cintala, M.J., Wood, C.A., Head, J.W., 1977. The effects of target characteristics on fresh crater morphology - Preliminary results for the Moon and Mercury. Proc. Lunar Planet. Sci. 8, 3409-3425.

Cintala, M.J., Head, J.W., Veverka, J., 1978. Characteristics of the cratering process on small satellites and asteroids. Proc. Lunar Planet. Sci. Conf. 9, 3803-3830.

Denevi, B.W. et al., 2009. The evolution of Mercury's crust: A global perspective from MESSENGER. Science 324, 613-619.

Dzurisin, D., 1978. The tectonic and volcanic history of Mercury as inferred from studies of scarps, ridges, troughs, and other lineaments. J. Geophys. Res. 83 , 4883-4906.

Fujiwara, A., Kadono, T., Nakamura, A., 1993. Cratering experiments into curved surfaces and their implication for craters on small satellites. Icarus 105, 345 350 .

Fulmer, C.V., Roberts, W.A., 1963. Rock induration and crater shape. Icarus 2, 452465.

Garvin, J.B., Frawley, J.J., 1998. Geometric properties of martian impact craters: Preliminary results from the Mars Orbiter Laser Altimeter. Geophys. Rev. Lett. 25, 4405-4408.

Gaskell, R.W. et al., 2008. Characterizing and navigating small bodies with imaging data. Meteorit. Planet. Sci. 43, 1049-1061.

Gault, D.E., Wedekind, J.A., 1977. Experimental hypervelocity impact into quartz sand - II, effects of gravitational acceleration. In: Roddy, D.J., Pepin, R.O., Merril, R. (Eds.), Impact and Explosion Cratering. Pergamon, New York, NY, pp. 1231 1260.

Gault, D.E., Wedekind, J.A., 1978. Experimental studies of oblique impact. Proc. Lunar Planet. Sci. Conf. 9, 3843-3875.

Gault, D.E., Quaide, W., Oberbeck, V., 1968. Impact cratering mechanics and structures. In: French, B., Short, N.M. (Eds.), Shock Metamorphism of Natura Materials. Mono Book Corp., Baltimore, MD, pp. 87-90.

Guest, J.E., Gault, D.E., 1976. Crater populations in the early history of Mercury Geophys. Res. Lett. 3, 121-123.

Gwinner, K., Hauber, E., Jaumann, R., Neukum, G., 2000. High-resolution, digital photogrammetric mapping: A tool for Earth science. EOS Am. Geophys. Union Trans. 81, 513-520.

Hartmann, W.K., 1981. Discovery of multi-ring basins - Gestalt perception in planetary science. In: Merill, R.B., Schultz, P.H. (Eds.), Multi-ring Basins: Formation and Evolution. Pergamon Press, New York, NY, pp. 79-90.

Head, J.W., Wood, C.A., Cintala, M.J., 1976. Morphological degradation of mercurian craters. Conference on Comparisons of Mercury and the Moon, LP Contributions 262, 15-17.

Head, J.W. et al., 2008. Volcanism on Mercury: Evidence from the first MESSENGER flyby. Science $321,69-72$.
Head, J.W. et al., 2009. Volcanism on Mercury: Evidence from the first MESSENGER flyby for extrusive and explosive activity and the volcanic origin of plains. Earth Planet. Sci. Lett. 285, 227-242.

Holsapple, K.A., 1993. The scaling of impact processes in planetary sciences. Ann. Rev. Earth Planet. Sci. 21, 333-373.

Horedt, G.P., Neukum, G., 1984. Planetocentric versus heliocentric impacts in the jovian and saturnian satellite system. J. Geophys. Res. 89, 10405-10410.

Housen, K.R., Holsapple, K.A., 2003. Impact cratering on porous asteroids. Icarus $163,102-119$.

Housen, K.R., Holsapple, K.A., 2011. Ejecta from impact craters. Icarus 211 (1), 856 875.

Le Feuvre, M., Wieczorek, M.A., 2008. Nonuniform cratering of the terrestrial planets. Icarus 197, 291-306.

Malin, M.C., Dzurisin, D., 1977. Landform degradation on Mercury, the Moon, and Mars - Evidence from crater depth/diameter relationships. J. Geophys. Res. 82, 376-388.

Malin, M.C., Dzurisin, D., 1978. Modification of fresh crater landforms - Evidence from the Moon and Mercury. J. Geophys. Res. 83, 233-243.

McCauley, J.F., Guest, J.E., Schaber, G.G., Trask, N.J., Greeley, R., 1981. Stratigraphy of the Caloris basin, Mercury. Icarus 47, 184-202.

Murchie, S.L. et al., 2008. Geology of the Caloris basin, Mercury: A view from MESSENGER. Science 321, 73-76.

Neukum, G., Ivanov, B.A., 1994. Crater size distributions and impact probabilities on Earth from Lunar, terrestrial-planet, and Asteroid cratering data. In: Gehrels, T. Matthews, M.S., Schumann, A.M. (Eds.), Hazards Due to Comets and Asteroids. University of Arizona Press, Tuscon, AZ, pp. 359-416.

Oberbeck, V.R., Quaide, W.L., Arvidson, R.E., Aggarwal, H.R., 1977. Comparative studies of Lunar, martian, and mercurian craters and plains. J. Geophys. Res. 82, 1681-1698.

Oberst, J., Preusker, F., Phillips, R.J., Watters, T.R., Head, J.W., Zuber, M.T., Solomon, S.C., 2010. The morphology of Mercury's Caloris basin as seen in MESSENGER stereo topographic models. Icarus 209, 230-238.

Pike, R.J., 1974. Depth/diameter relations of fresh lunar craters - Revision from spacecraft data. Geophys. Res. Lett. 1, 291-294.

Pike, R.J., 1976. Crater dimensions from Apollo data and supplemental sources. Moon 15, 463-477.

Pike, R.J., 1977. Size-dependence in the shape of fresh impact craters on the Moon In: Roddy, D.J., Pepin, R.O., Merrill, R.B. (Eds.), Impact and Explosion Cratering: Planetary and Terrestrial Implications. Pergamon, New York, NY, pp. 489-509.

Pike, R.J., 1980. Control of crater morphology by gravity and target type - Mars, Earth, Moon. Proc. Lunar Planet. Sci. Conf. 10, 2159-2189.

Pike, R.J., 1988. Geomorphology of impact craters on Mercury. In: Vilas, F. Chapman, C.R., Matthews, M.S. (Eds.), Mercury. University of Arizona Press, Tuscon, AZ, pp. 165-273.

Pohn, H.A., Offield, T.W., 1970. Lunar crater morphology and the relative age determination of lunar geological units. Part I. Classification. US Geol. Survey Prof. Paper 700.

Robinson, M.S., Davies, M.E., Colvin, T.R., Edwards, K., 1999. A revised control network for mercury. J. Geophys. Res. 104, 30847-30852.

Schenk, P.M., 2002. Thickness constraints on the icy shells of the Galilean satellites from a comparison of crater shapes. Nature 417, 419-421.

Scholten, F., Gwinner, K., 2004. Operational parallel processing in digital photogrammetry - Strategy and results using different multi-line cameras. Inter. Arch. Photogramm. Remote Sens. 34, 408-413.

Scholten, F., Gwinner, K., Roatsch, T., Matz, K.-D., Waehlisch, M., Giese, B., Oberst, J., Jaumann, R., Neukum, G., The HRSC Co-Investigator Team, 2005. Mars Express HRSC data processing - Methods and operational aspects. Photogramm. Eng. Remote Sens. 71, 1143-1152.

Schultz, P.H., 1988. Cratering on Mercury - A relook. In: Vilas, F., Chapman, C.R., Matthews, M.S. (Eds.), Mercury. University of Arizona Press, Tuscon, AZ, pp. 274-335.

Schultz, P.H., Ernst, C.M., Anderson, J.L.B., 2005. Expectations for crater size and photometric evolution from the Deep Impact collision. Space Sci. Rev. 117, 207 239.

Shoemaker, E.M., 1963. Impact mechanics at Meteor Crater, Arizona. In: Middlehurst, B.M., Kuiper, G.P. (Eds.), The Moon, Meteorites and Comets. Univ. of Chicago Press, Chicago, pp. 301-336.

Spudis, P.D., Guest, J.E., 1988. Stratigraphy and geologic history of Mercury. In: Vilas, F., Chapman, C.R., Matthews, M.S. (Eds.), Mercury. University of Arizona Press, Tuscon, AZ, pp. 118-164.

Spudis, P.D., Prosser, J.G., 1984. Geological Map of the Michelangelo quadrangle (H12) of Mercury. US Geol. Survey Map I-1659.

Strom, R.G., Malhotra, R., Ito, T., Yoshida, F., Kring, D.A., 2005. The origin of planetary impactors in the inner Solar System. Science 309, 1847-1850.

Strom, R.G., Chapman, C.R., Merline, W.J., Solomon, S.C., Head, J.W., 2008. Mercury cratering record viewed from MESSENGER's first flyby. Science 321, 79-81.

Wewel, F., Scholten, F., Gwinner, K., 2000. High Resolution Stereo Camera (HRSC) Multispectral 3D-data acquisition and photogrammetric data processing. Can. J. Remote Sens. 26, 466-474.

Wilhelms, D.E., 1976. Mercurian volcanism questioned. Icarus 28, 551-558.

Zuber, M.T. et al., 2008. Laser altimeter observations from MESSENGER's first Mercury flyby. Science 321, 77-79.

Zuber, M.T. et al., 2012. Topography of the Northern Hemisphere of Mercury from MESSENGER Laser altimetry. Science, doi:10.1126/science.1218805. 